\title{
Ocean Response to CINDY/DYNAMO MJOs in Air-Sea-Coupled COAMPS
}

\author{
Tommy G. JENSEN \\ Oceanography Division, Naval Research Laboratory, Stennis Space Center, Mississippi, USA \\ Toshiaki SHINODA \\ Texas A\&M University, Corpus Christi, Texas, USA \\ Sue CHEN, and Maria FLATAU \\ Marine Meteorology Division, Naval Research Laboratory, Monterey, California, USA \\ (Manuscript received 17 February 2015, in final form 25 July 2015)
}

\begin{abstract}
The response of the ocean to three Madden-Julian Oscillation (MJO) events during the fall of 2011 is simulated by the Coupled Ocean-Atmosphere Mesoscale Prediction System (COAMPS) in a fully coupled mode with high resolution in the atmosphere and ocean. The model simulates the cooler sea surface temperature (SST) and disappearance of the diurnal cycle in SST during the active phase of the MJO and it compares well with the observed SST from Research Moored Array for African-Asian-Australian Monsoon Analysis and Prediction (RAMA) buoys. The most striking direct response to the westerly zonal wind stress associated with the onset of the MJO is a rapidly accelerating Yoshida jet in the ocean mixed layer with equatorial zonal currents exceeding $1 \mathrm{~m} \mathrm{~s}^{-1}$. These jets are found in the model as well as the RAMA buoy observations. In the model, the Yoshida jet is superimposed on the seasonal Wyrtki jet that has a subsurface local maximum between 50 and $150 \mathrm{~m}$. A shear layer separates the subsurface seasonal jet and the surface jet forced by the MJO. The sea surface elevation response and upper ocean heat content show wind generated westward propagating Rossby waves symmetric around the equator and an associated eastward propagating equatorial Kelvin wave response. After the third MJO event, the Yoshida jet spans most of the equatorial Indian Ocean. Upon reaching the Indonesian coast, the associated equatorial Kelvin wave reflects and generates additional westward propagating equatorial Rossby waves. The volume transport associated with these waves causes the westward advection of low-salinity north and south of the equator, impacting the tropical ocean circulation.
\end{abstract}

Keywords air-sea interaction; equatorial currents; intra-seasonal oscillations; coupled model

\section{Introduction}

The most important impact on the tropical Indian

Corresponding author: Tommy G. Jensen, Oceanography Division, Naval Research Laboratory, Stennis Space Center, Code 7322, 1009 Balch Boulevard, Stennis Space Center, Mississippi 39529-5004, USA

E-mail: Tommy.Jensen@nrlssc.navy.mil

(C)2015, Meteorological Society of Japan
Ocean is the annual reversal of the Indian monsoon that changes from strong southwesterly winds during the boreal summer to less intense northeasterlies during the northern winter. The southwest monsoon drives an upper ocean circulation in the northern Indian Ocean as a clockwise gyre with an eastward flow in the Southwest Monsoon Current north of the equator and a southern hemisphere return flow in the South Equatorial Current during the boreal summer. 
During the boreal winter, the flow north of the equator is reversed as the Northeast Monsoon Current flows westward, with the eastward flowing South Equatorial Counter Current closing an anti-clockwise circulation spanning a much smaller area than that of the gyre during the northern summer (e.g., Schott and McCreary 2001; Schott et al. 2009). However, the Madden-Julian Oscillation (MJO) and intra-seasonal variability account for a large change in the forcing of the tropical Indian Ocean on seasonal time scales between 30-60 days (Madden and Julian 1972; Zhang 2005; 2013). This variability is largest outside the Indian summer-monsoon season.

During the monsoon transitions in April-May and October-November, jets with current speeds of approximately $1 \mathrm{~m} \mathrm{~s}^{-1}$ appear along the equator (Wyrtki 1973). These seasonal equatorial jets, referred to as Wyrtki jets (WJs), appear twice a year. They were explained as a wind-driven response to zonal winds by O'Brien and Hurlburt (1974), who applied the theory of Yoshida (1959). The WJs have been observed to appear in the spring and the fall of every year on a regular basis (e.g., Nagura and McPhaden 2010; Nyadjro and McPhaden 2014), although the spring jets have been found to be weak in 2006 through 2009 (Joseph et al. 2012). The strong response of the WJ to semi-annual forcing has been explained by resonant basin modes (Jensen 1993; Han et al. 1999) based on the theoretical work of Cane and Moore (1981). Hence, the WJ is a seasonal large scale phenomenon.

Associated with the MJO are strong westerly surface winds along the equator that last for several days as they propagate eastward. These wind events can rapidly accelerate the upper ocean and generate an equatorial jet, as predicted by the theory of Yoshida (1959). We will therefore refer to these locally generated jets of short duration as Yoshida jets to distinguish them from the WJ.

It is well known that the MJO has a large impact on the sea surface temperature (SST) in the Indian Ocean as increased zonal winds increase latent heat flux, induce vertical mixing, and increased cloud cover reduces solar insolation (e.g., Shinoda et al. 1998; Shinoda 2005; Shinoda et al. 2013a; Zhang 2005, 2013). In addition to mixed layer (ML) temperature variations from local heat fluxes, there is a dynamic wave response causing the horizontal or vertical advection of heat and freshwater. Oceanic Kelvin waves have been hypothesized to steepen and possibly break causing sharp SST fronts and the advection of SST anomalies (Fedorov and
Melville 2000). A deep ocean temperature response has also been detected in Argo floats down to 1000 $\mathrm{m}$ (Matthews et al. 2007), which they ascribe to forced Kelvin waves. It has also been noted that ocean Kelvin waves change period and phase speed as a direct result of continued atmospheric forcing under MJO westerly wind bursts (Kessler et al. 1995; Shinoda et al. 2008). Finally, the reflection of the equatorial Kelvin wave on the coast of Sumatra leads to westward propagating equatorial Rossby waves and poleward propagating coastal Kelvin waves that modify the Indian Ocean circulation after a MJO event (Webber et al. 2012; Shinoda et al. 2013b). These results show that the ocean circulation is being actively forced by the MJO, but the mechanism for the feedback from the ocean to the MJO via SST and fluxes is less understood (Flatau et al. 1997; Waliser et al. 1999; Maloney and Kiehl 2002).

\section{Objectives, experiments, and methods}

In this study, we investigate the equatorial response of the upper ocean to three MJO events in the fall of 2011 during the Dynamics of the Madden-Julian Oscillation (DYNAMO) field campaign. Compared with previous works that focus on the predictability of the MJO caused by a thermally active ocean (e.g., Fu et al. 2008; see also Zhang 2013), we explore the direct upper ocean response in terms of accelerating equatorial jets and the mixed layer response in a tightly coupled high-resolution ocean-atmosphere model. The coupled model is described below with details for the ocean component. Changes in sea surface temperature, mixed layer depth (MLD), and the diurnal cycle of those quantities are then presented and discussed. This includes a comparison of SST from the Coupled Ocean-Atmosphere Mesoscale Prediction System (COAMPS) and several RAMA buoy sites. Next, we explore the response of surface and mixed layer currents. Currents at two RAMA buoy sites are compared with the COAMPS currents. The model response in terms of equatorial jets in the mixed layer is analyzed in more detail. Finally, we discuss the basin wide changes in the oceanic heat content from COAMPS during the MJO events and the impact on the advection of low-salinity water in the eastern Indian Ocean.

\section{Coupled Ocean-Atmospheric Mesoscale Predic- tion System (COAMPS)}

For the simulations of the atmospheric and oceanic conditions, we use COAMPS in a fully coupled mode (Allard et al. 2010). Details about the atmospheric 
model can be found in Hodur (1997) and Chen et al. (2003), and the application of the coupled model has been given by Chen et al. (2010); Jensen et al. (2011). COAMPS was also used in a fully coupled configuration for the simulation of a 2009 MJO event by Shinoda et al. (2013a). The model atmosphere assimilates observed data using a 3-dimensional adjoint method (Langland and Baker 2004). The model covers the Indian Ocean north of $28^{\circ} \mathrm{S}$ and from the coast of Africa to $140^{\circ} \mathrm{E}$ including a part of the western Pacific (Fig. 1). The atmosphere model has a $27-\mathrm{km}$ resolution with an inner nest of $9-\mathrm{km}$ resolution covering the DYNAMO region of $66^{\circ} \mathrm{E}-85^{\circ} \mathrm{E}$, $10^{\circ} \mathrm{S}-5^{\circ} \mathrm{N}$ and uses 40 vertical levels. The coupling interval between the atmosphere and ocean models is $6 \mathrm{~min}$. The fast coupling interval ensures that air-sea fluxes remain in balance even for rapidly developing events.

\section{Navy coastal ocean model}

The ocean model used is the Navy Coastal Ocean Model (NCOM) developed at the Naval Research Laboratory (Martin 2000). The model has a hybrid sigma-z vertical coordinate and free surface. It was originally based on the Princeton Ocean Model (POM) by Blumberg and Mellor (1987) and has many aspects common with POM. For instance, it is using the same C-grid layout, equation of state (Mellor 1991), and 2.5-level turbulent closure scheme for vertical mixing (Mellor and Yamada 1982). A notable difference is the treatment of the barotropic mode. NCOM employs a semi-implicit scheme that uses a pre-conditioned conjugate gradient solver for the resulting elliptic equation, whereas POM uses an explicit scheme with time-splitting. A thirdorder upwind leapfrog advection scheme (Holland et al. 1998) is used for the advection of scalar quantities and momentum in this NCOM simulation rather than the traditional second-order leapfrog scheme with sub-gridscale horizontal mixing (Smagorinsky 1963) that is traditionally used in the global versions of NCOM and in POM, and a fourth-order accurate calculation is used for the pressure gradient and Coriolis terms. The ocean model also includes river runoff from monthly climatology and eight major diurnal and semi-diurnal tidal constituents (K1, O1, P1, Q1, $\mathrm{K} 2, \mathrm{M} 2$, N2, and S2).

A single grid covers the active ocean model using a uniform resolution of $1 / 8^{\circ}$ in spherical coordinates on a $811 \times 433$ grid with a time step of $40 \mathrm{~s}$. There are 60 vertical levels: 45 sigma levels with $15 \mathrm{z}$-levels below depths of $330 \mathrm{~m}$. An unusually high vertical resolution of $0.5 \mathrm{~m}$ between the surface and $10-\mathrm{m}$ depth ensures a much better resolution of the diurnal cycle than that commonly available in 3D circulation models.

\section{Initial and boundary conditions}

Initial and boundary conditions to the atmospheric model come from the Navy Operational Global Atmospheric Prediction System (NOGAPS) and observations. For 1 Oct. 2011 at 0000 UTC, the atmospheric model is initialized using quality-controlled observations from surface stations, ships, radiosondes, aircrafts, satellites, and a 12-hour NOGAPS forecast with a spatial resolution of $1^{\circ} \times 1^{\circ}$. The observations and NOGAPS forecast are analyzed using the Naval Research Laboratory Atmospheric Variational Data Assimilation System (NAVDAS) and projected onto the atmospheric forecast model grids. The boundary conditions provided by NOGAPS are updated every 6 hours. A re-analysis that assimilates new observations into the atmospheric model forecast is done every 12 hours before the atmospheric model run is continued. This ensures that the atmospheric model simulation remains realistic over the 3-month-long DYNAMO experiment.

The ocean model is initialized, and its boundaries forced every 6 hours by the output from the $1 / 8^{\circ}$ global NCOM (GNCOM) with 41 vertical levels (Barron et al. 2006), and the surface forcing is provided by NOGAPS. Outside the active ocean model area, e.g., the larger box outlined in red in Fig. 1, the SST used to compute fluxes to the atmosphere model is from the Navy Coupled Ocean Data Assimilation (NCODA) analysis (Cummings 2005). This is a standard setup for COAMPS when run without an active ocean. Tides at the boundaries are computed using the Oregon State University TOPEX/Poseidon Global Inverse Solution (TPXO), as described by Egbert et al. (1994) and Egbert and Erofeeva (2002). NCOM supports data assimilation using multivariate optimal interpolation (Cummings 2005), but it was deliberately not used to allow a free simulation of the oceanic variability in the coupled model.

\section{RAMA buoys}

A great asset for ocean science is the Research Moored Array for African-Asian-Australian Monsoon Analysis and Prediction (RAMA) project that operates moored buoys in the Indian Ocean. The program is led by the National Oceanographic and Atmospheric Administration (NOAA) in the U.S.A., with contributions from institutions in Japan, India, Indonesia, China, Africa, France, and Thailand (McPhaden et al. 


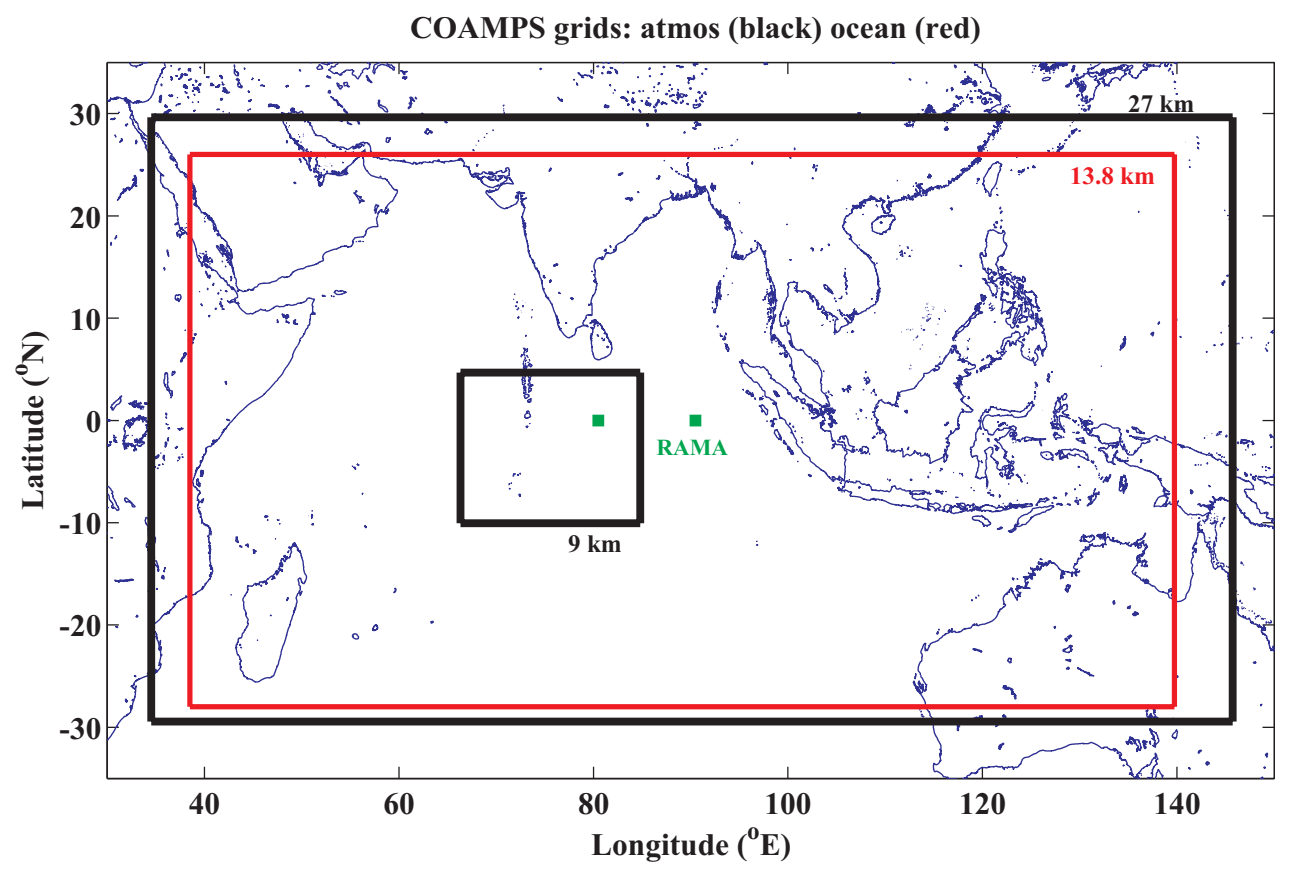

Fig. 1. Model areas for the atmospheric model (black lines) and ocean models (red lines). The location of the two RAMA buoys on the equator within the DYNAMO region is shown in green.

2009). The RAMA now has more than 30 operational sites. Several moorings are located in the vicinity of the equator at $80.5^{\circ} \mathrm{E}$ and $90^{\circ} \mathrm{E}$ and measure surface meteorology with a 10-minute interval. In the ocean, temperature, salinity, and currents were measured up to a depth of $500 \mathrm{~m}$. In this work, we use two moorings on the equator at $80.5^{\circ} \mathrm{E}$ and $90^{\circ} \mathrm{E}$ for current meter observations and SST. Additional SST observations are used along $80.5^{\circ} \mathrm{E}$ at $4^{\circ} \mathrm{S}$ and $8^{\circ} \mathrm{S}$ and from a mooring at $90^{\circ} \mathrm{E}$ and $1.5^{\circ} \mathrm{N}$.

\section{Equatorial response during DYNAMO}

The active phase of the MJO is characterized by strong westerly winds along the equator. Figure 2 shows the zonal wind stress component along the equator, computed as the daily mean and averaged from $5^{\circ} \mathrm{S}-5^{\circ} \mathrm{N}$. The wind stress is used to define the onset and duration of three MJO events that forces the ocean with an increased eastward momentum flux and changes in net surface heat from a net warming to a net cooling of the ocean. The zonal wind stress in Fig. 2 suggests active MJO phases in three events: MJO1 from 15 Oct. to 2 Nov. MJO2 from 23 Nov to 6 Dec, and MJO3 from 15 Dec to Dec 31. The same three events can be seen in rainfall from the Tropical Rainfall Measuring Mission (TRMM), which tradi- tionally has been used to help define MJO onset and the duration of the DYNAMO MJO events by several authors (e.g., Shinoda et al. 2013b; Matthews et al. 2014; Chen et al. 2015). In Fig. 3 (left), the time evolution from 1 Oct. to $31 \mathrm{Dec}$. of the daily SST maximum averaged $5^{\circ} \mathrm{S}-5^{\circ} \mathrm{N}$ is shown as a function of longitude. Near the African coast, southerly winds keep the SST low until the end of October and the wind from the north keeps the SST low in December. In the central Indian Ocean, maximum SST is above $30^{\circ} \mathrm{C}$ during the suppressed phases of the MJO. During the active phases, SST drops by approximately $1{ }^{\circ} \mathrm{C}$, most significantly east of $75^{\circ} \mathrm{E}$. Not only is the daily maximum temperature changed, but the amplitude of the diurnal cycle is affected as well. The magnitude of the diurnal cycle of SST can be above $1.5^{\circ} \mathrm{C}$ and is found in the equatorial Indian Ocean during the suppressed phase of the MJO (Fig. 3 , right panel). This near-surface diurnal warm layer was observed using Seaglider observations during the inactive phase of the MJO during DYNAMO (Matthews et al. 2014). This diurnal SST cycle is strongly dampened or may completely disappear during the active MJO phase. The combined effect of increasing wind speed and latent heat flux and decreasing solar flux contributes to the cooling and 


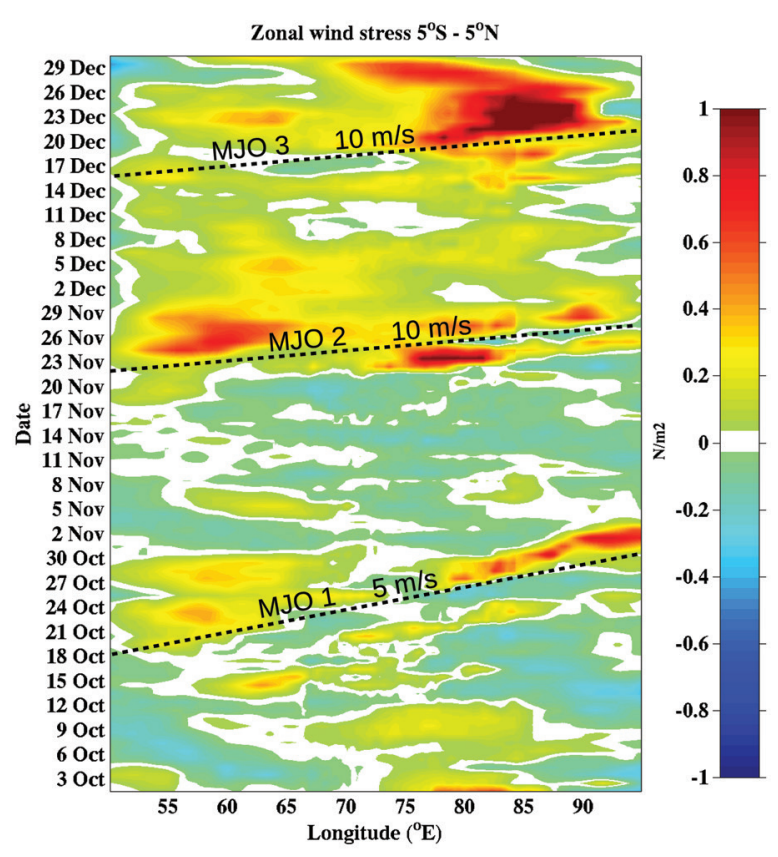

Fig. 2. Time-longitude plot of daily mean zonal wind stress component along the equator from 1 Oct. to 31 Dec. 2011. An average from $5^{\circ} \mathrm{S}$ to $5^{\circ} \mathrm{N}$ is used.

shuts off the diurnal cycle of SST. The strong wind (Fig. 2) during the MJO increases vertical mixing, which also will decrease the diurnal amplitude in SST. Figure 4 shows the daily minimum MLD during the simulation. The MLD is defined here as the depth where an increase in density, equivalent to a temperature decrease of $0.3^{\circ} \mathrm{C}$, is found, when compared with the density at $1 \mathrm{~m}$. When a strong diurnal cycle is present in SST, temperature stratification near the surface will lower the MLD during the day. However, during the active phase of the MJO, wind mixing and a lack of incoming solar radiation keep the MLD for consistency deeper than $20 \mathrm{~m}$ in the central Indian Ocean (Fig. 4).

\section{Comparison of SST between RAMA buoys and COAMPS}

The ocean component does not include data assimilation of any variables. The RAMA buoy observation of ocean parameters can be used for the validation of COAMPS. However, air temperature is assimilated into the atmospheric model, which provides an indirect relaxation of SST to near observed SST through the sensible heat flux. Figure 5 shows the
SST on the equator at $80.5^{\circ} \mathrm{E}$. For the RAMA observations, SST refers to the temperature at $1 \mathrm{~m}$, while it is the temperature at $0 \mathrm{~m}$ for COAMPS. At that location, the data availability ended on 23 Nov at the buoy. COAMPS has a small positive bias until early November when COAMPS starts to become colder than the buoy observation by nearly $1{ }^{\circ} \mathrm{C}$. Without a heat budget, which cannot be done since heat advection is not available from the RAMA buoy observations, the exact cause for this discrepancy cannot be determined. However, a contributing factor might be that the daily averaged solar radiation at the RAMA buoy was nearly $50 \mathrm{~W} \mathrm{~m}^{-2}$ larger than COAMPS between 10 Nov. and 22 Nov. 2011. The magnitude of the diurnal cycle in COAMPS tends to be larger than the observations. In COAMPS, it can reach $2^{\circ} \mathrm{C}$, while the maximum observed is $1.5^{\circ} \mathrm{C}$. However, during calm condition, the daytime maximum in COAMPS at $1 \mathrm{~m}$ is up to $0.25^{\circ} \mathrm{C}$ cooler than at the surface at $0 \mathrm{~m}$ (Shinoda et al. 2013a). Since COAMPS SST is at $0 \mathrm{~m}$ and RAMA SST is at $1 \mathrm{~m}$, this may explain the difference between the observation and model SSTs. We chose to use $0 \mathrm{~m}$ rather than $1 \mathrm{~m}$ temperature from COAMPS because subsurface model temperatures are only available every 3 hours from the model output. Note that the diurnal cycle in SST is suppressed starting 23 Oct. after MJO1 winds reach the RAMA buoy at $80.5^{\circ} \mathrm{E}$ (see Fig. 2). Figure 6 shows the hourly SST during 1 Oct.-31 Dec. 2011 at four other RAMA buoy locations in the vicinity of the equator. We find some differences in SST between the buoy and the model, but COAMPS do not have a consistent warm or cold bias. At $80.5^{\circ} \mathrm{E}, 4^{\circ} \mathrm{S}$ COAMPS have a warm bias of just under $0.1^{\circ} \mathrm{C}$ over three months, while the three other locations have a cold bias of the same magnitude or less. The largest COAMPS cold bias over three months was $0.13^{\circ} \mathrm{C}$ at the buoy location at $95^{\circ} \mathrm{E}, 5^{\circ} \mathrm{S}$, while the largest warm bias was $0.17^{\circ} \mathrm{C}$ at the buoy location at $95^{\circ} \mathrm{E}, 5^{\circ} \mathrm{S}$.

In a detailed analysis and comparison between COAMPS SST and surface fluxes and observations from the R/V Revelle from 12-16 Nov, during the suppressed phase of the MJO (Chen et al. 2015), COAMPS had a positive SST bias of $0.01^{\circ} \mathrm{C}$, but RMS errors of $0.46^{\circ} \mathrm{C}$. This suggests that the overall model SST bias is small, but the instantaneous SST differences between the model and the buoy are at times significant. These differences are to some extent caused by a delayed maximum in the COAMPS SST each day. Small phase differences in the time of daily maximum COAMPS SST can also be found when compared with the RAMA moorings SST. However, 

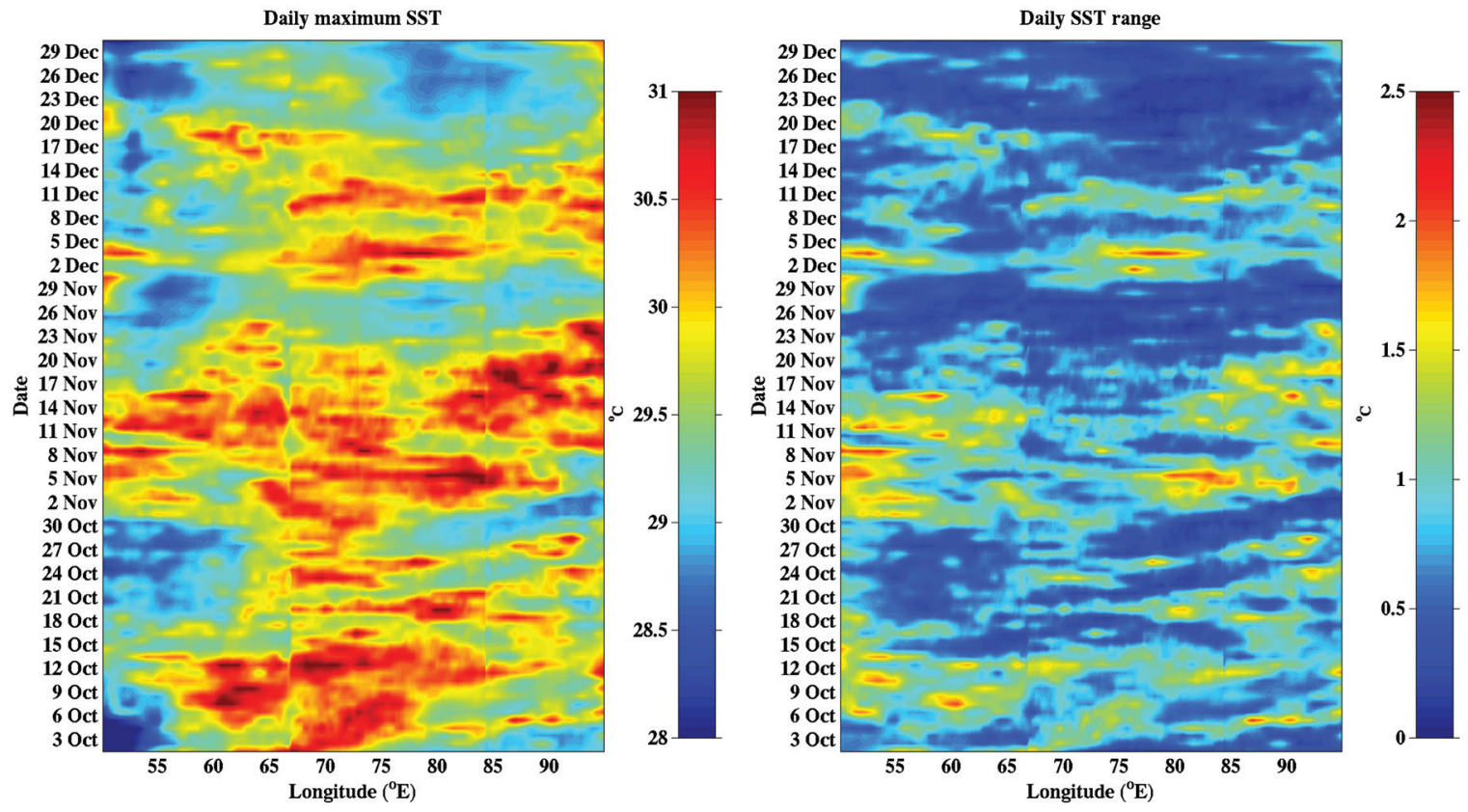

Fig. 3. Time-longitude plot of daily maximum sea surface temperature (left) and daily temperature range (right). Unit is degree Celsius and a spatial average from $5^{\circ} \mathrm{S}$ to $5^{\circ} \mathrm{N}$ is used.
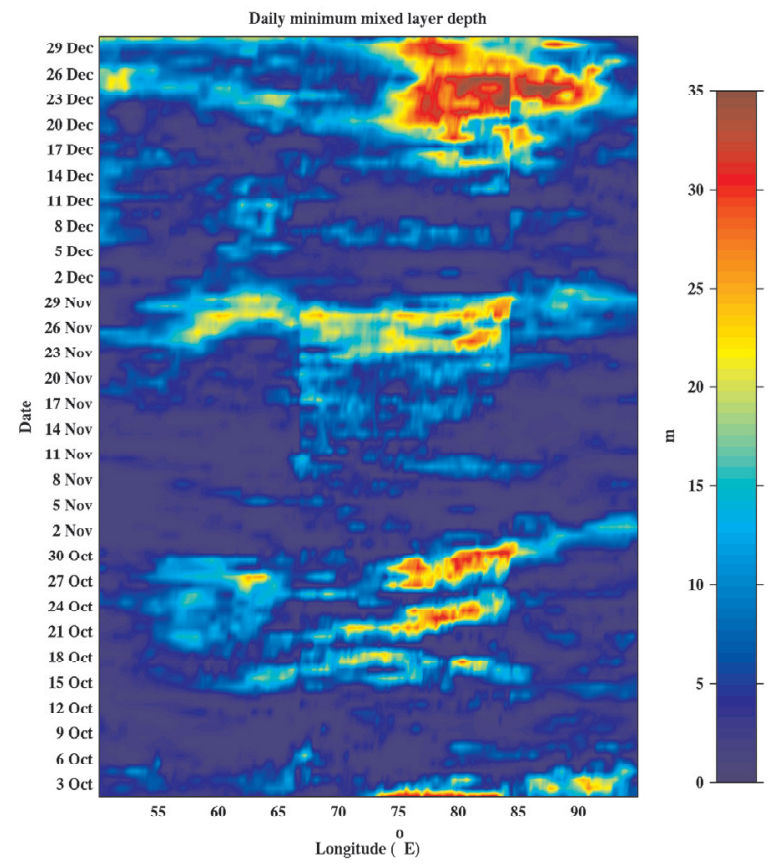

Fig. 4. Time-longitude plot of daily minimum sea mixed layer depth from 1 Oct. to 31 Dec. 2011. The depth is an average from $5^{\circ} \mathrm{S}$ to $5^{\circ} \mathrm{N}$ along the equator. the COAMPS SST daily maximum does not consistently lag the observed time of maximum RAMA SST but can also be found to lead the RAMA observation.

\section{Surface current variability along the equator}

The COAMPS simulation starts near the end of the southwest monsoon season when the winds begin to relax. At that time, the eastward flowing Southwest Monsoon Current, which spans from southern India to about $5^{\circ} \mathrm{S}$ and the African coast to Indonesia, has slowed down. Figure 7 shows the time-longitude plot of the daily averaged zonal velocity component at the sea surface. An average from $5^{\circ} \mathrm{S}$ to $5^{\circ} \mathrm{N}$ is shown. Currents are weak and an eastward current is propagating westward from $80^{\circ} \mathrm{E}$ on 1 Oct. reaching $70^{\circ} \mathrm{E}$ on 8 Nov.. The propagation is about $0.3-0.4 \mathrm{~m} \mathrm{~s}^{-1}$ that might be attributed to a second baroclinic equatorial Rossby meridional mode 1 wave (Matsuno 1966; see also Pedlosky 1979, p. 592-596, or Gill 1982, p. 444-454). The active MJO events stand out as the eastward propagating strong zonal currents. They propagate eastward with a speed of $3.4 \mathrm{~m} \mathrm{~s}^{-1}$, corresponding to the phase speed of an equatorial Kelvin wave. The propagation speeds may also be calculated from sea level height (see Fig. 16). 


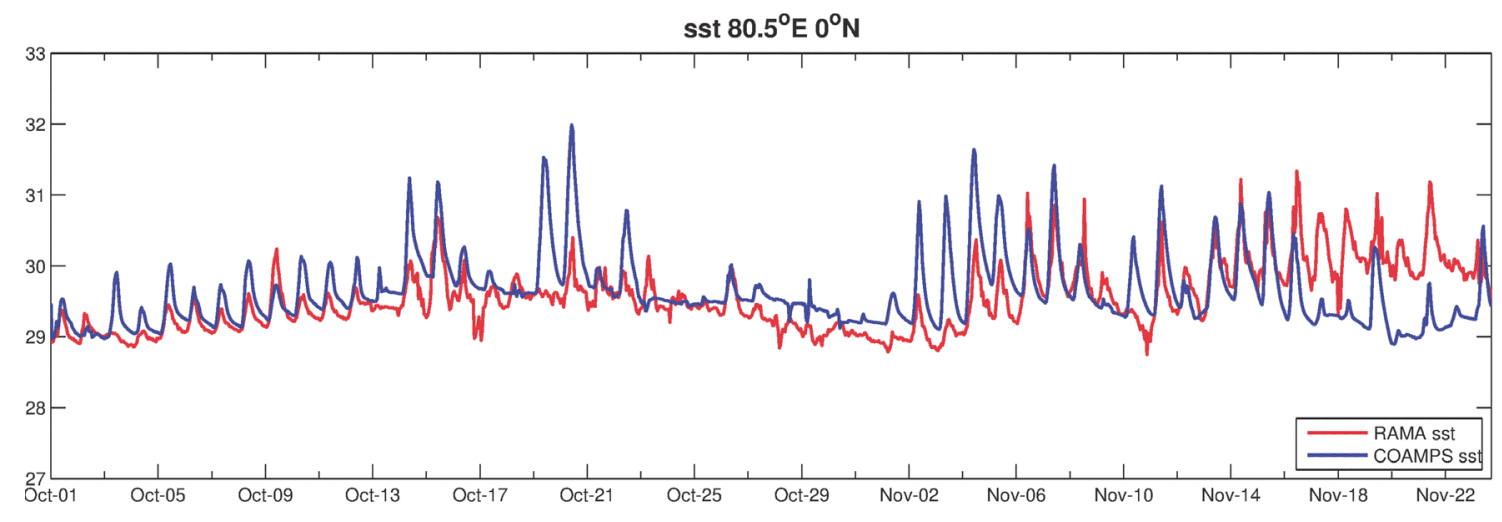

Fig. 5. Hourly sea surface temperature at RAMA mooring (red) and COAMPS (blue) at $80.5^{\circ} \mathrm{E}$ on the equator. Measurements were available from the start of the model that ran on 1 Oct. until 23 Nov. 2011 at this location.

\section{Comparison of currents between RAMA buoys and COAMPS}

In the open ocean, it is our experience that observed near-surface currents from a single buoy or ship location and model currents at the same site often show large differences except for averages over several months. However, since currents along the equator primarily are zonal, a comparison between the RAMA buoy and COAMPS currents will be given here. Subsurface currents are available from two RAMA buoys on the equator, one at $80.5^{\circ} \mathrm{E}$ with observations at 10 and $40 \mathrm{~m}$ and one at $90^{\circ} \mathrm{E}$ with $10 \mathrm{~m}$ currents. A 3-hour average was computed from the observations, which were taken every 30 minutes. This provides us with an assessment of the realism of the COAMPS/ NCOM simulation since the observed currents are not assimilated by our models. At $80.5^{\circ} \mathrm{E}$, the RAMA buoy (Fig. 8, top) shows a zonal current that is eastward throughout three months analyzed. It is also noticeable that there most often only are small differences between the RAMA current components at 10 $\mathrm{m}$ (red) and at $40 \mathrm{~m}$ (green) indicating that vertical shear is small. The COAMPS also show $10-\mathrm{m}$ and $40-\mathrm{m}$ current components that mostly vary in phase and with little shear, but events with shear occur more frequently than observed. The COAMPS zonal current at $80.5^{\circ} \mathrm{E}$ follows changes in phase of the observed currents on time scales of several days but is significantly weaker than the observed current. The response to $\mathrm{MJO} 2$, which caused a rapid acceleration of the currents on Nov 24, is captured very well, but the current is too weak, i.e., by a factor of 2 .

At $90^{\circ} \mathrm{E}$, the zonal currents from COAMPS completely miss a strong eastward current event in early October. The model currents are westward until the onset of MJO1 at that longitude on 1 Nov. The magnitude of the COAMPS zonal current is somewhat larger than observed, while the response to MJO2 on 28 Nov. is weaker than observed.

\section{Vertical structure of the equatorial jets}

In this section, we present the subsurface structure and evolution of the equatorial response to the MJOs. Figure 9 shows the cross sections of the zonal velocity between the surface and $200 \mathrm{~m}$ across the Indian Ocean from $55^{\circ} \mathrm{E}$ to $95^{\circ} \mathrm{E}$. At the start of the simulation on 1 Oct. (top panel), the surface expression of the seasonal WJ has vanished, while the subsurface current near $100 \mathrm{~m}$ is about $0.7 \mathrm{~m} \mathrm{~s}^{-1}$ east of $75^{\circ} \mathrm{E}$. In fact, the surface WJ was rather weak in the fall of 2011 (Joseph et al. 2012). MJO1 forced a strong eastward current in the western equatorial ocean on 20 Oct., as seen in Fig. 7. In addition to the Yoshida jet in the mixed layer, on 28 Oct. a strong eastward jet is found in the thermocline as well (Fig. 9, middle panel). While remnants of the fall WJ still were present, the subsurface jet intensified below the Yoshida jet in the mixed layer, suggesting local forcing. In the following suppressed phase of the $\mathrm{MJO}$, eastward currents are found in the thermocline, while ML currents are westward except near $80^{\circ} \mathrm{E}$ (Fig. 9, bottom panel). Figure 10 shows the initial response to MJO2 (top panel). Note that the first onset of strong westerly surface winds for that event is in the central equatorial Indian Ocean in the area $70^{\circ} \mathrm{E}-$ $82^{\circ} \mathrm{E}, 3^{\circ} \mathrm{S}-3^{\circ} \mathrm{N}$. This is followed by a second wind burst that starts west of $70^{\circ} \mathrm{E}$ and propagates along 

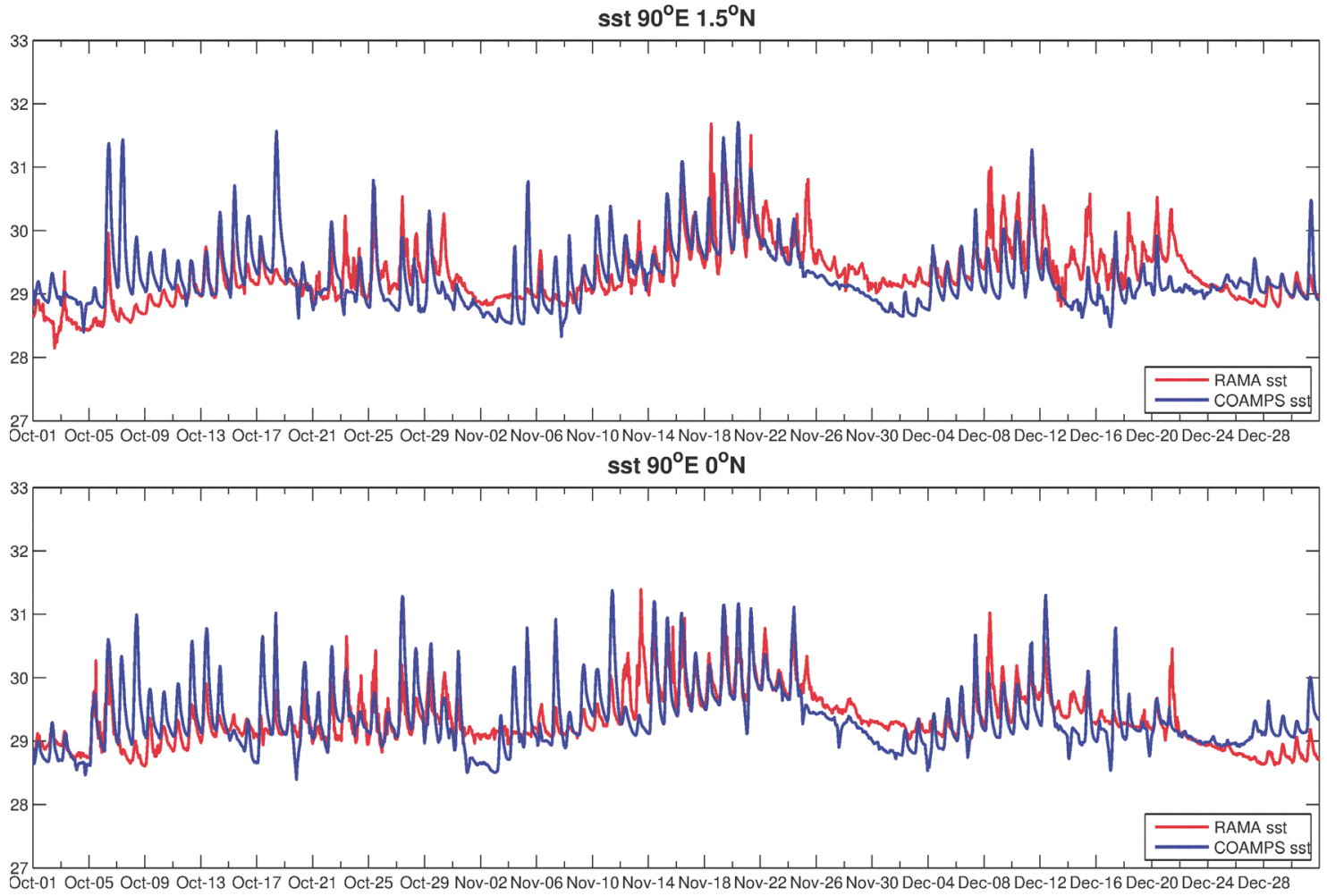

sst $80.5^{\circ} \mathrm{E} 4^{\circ} \mathrm{S}$

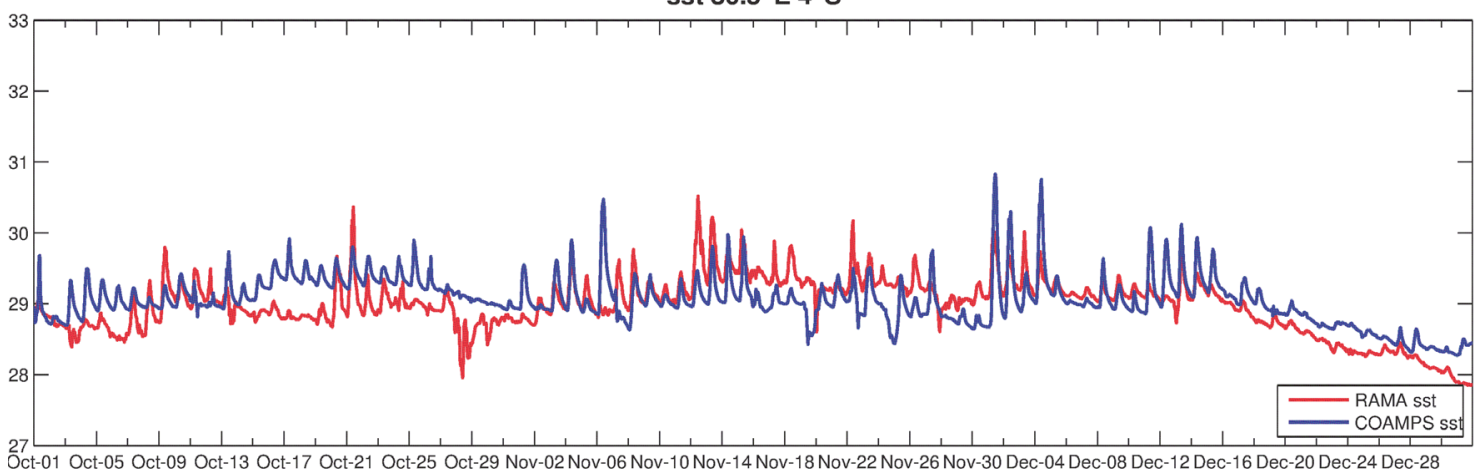

sst $80.5^{\circ} \mathrm{E} 8^{\circ} \mathrm{S}$

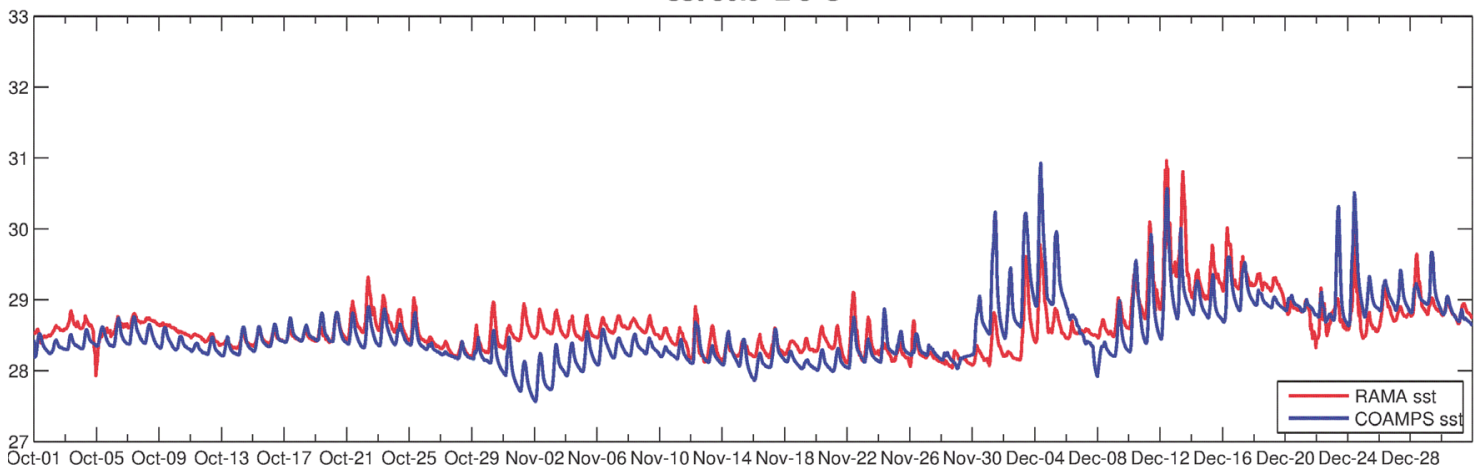

Fig. 6. Hourly sea surface temperature at RAMA moorings (red) and COAMPS (blue) in the vicinity of the equator from 1 Oct. to 31 Dec. 2011. 


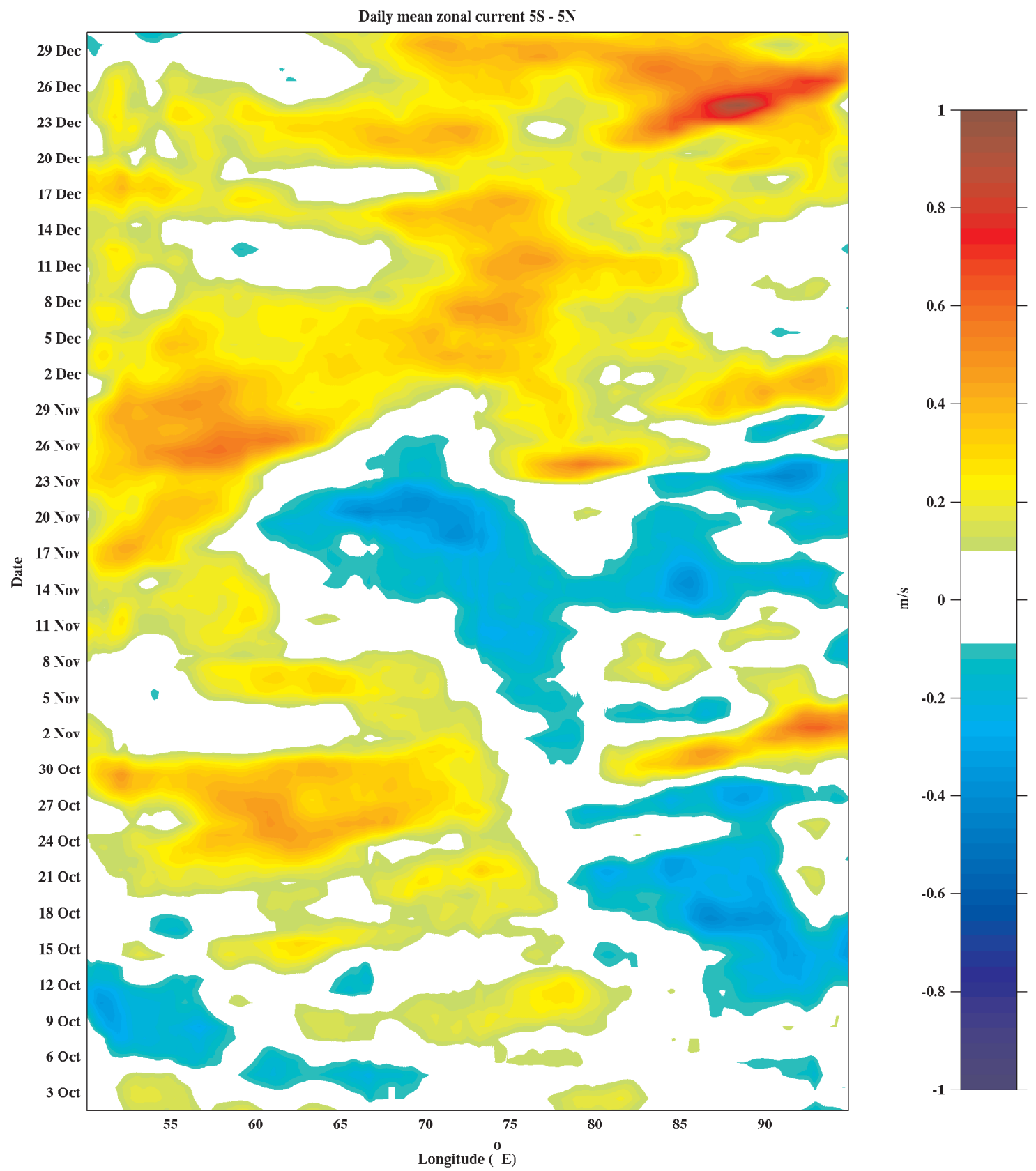

Fig. 7. Time-longitude plot of daily mean zonal current component from 1 Oct. to 31 Dec. 2011. An average is computed from $5^{\circ} \mathrm{S}$ to $5^{\circ} \mathrm{N}$ to represent the zonal current component along the equator.

the equatorial Indian Ocean with a phase speed of 10 $\mathrm{m} \mathrm{s}^{-1}$ (Fig. 2). The middle panel in Fig. 10 shows this dual response on 29 Nov. 2011. The zonal westerly winds of moderate strength prevail until 20 Dec. when a third MJO event produces a strong zonal wind near $85^{\circ} \mathrm{E}$. By the end of December, the entire mixed layer has eastward zonal velocities above $0.6 \mathrm{~m} \mathrm{~s}^{-1}$, which is also recorded by the RAMA buoys at $80.5^{\circ} \mathrm{E}$ and $90^{\circ} \mathrm{E}$ (Fig. 8).

Figures 11 and 12 show the equatorial cross sections at $80.5^{\circ} \mathrm{E}$ for the same time as the longitudinal sections in Fig. 9 and Fig. 10. The core of the 

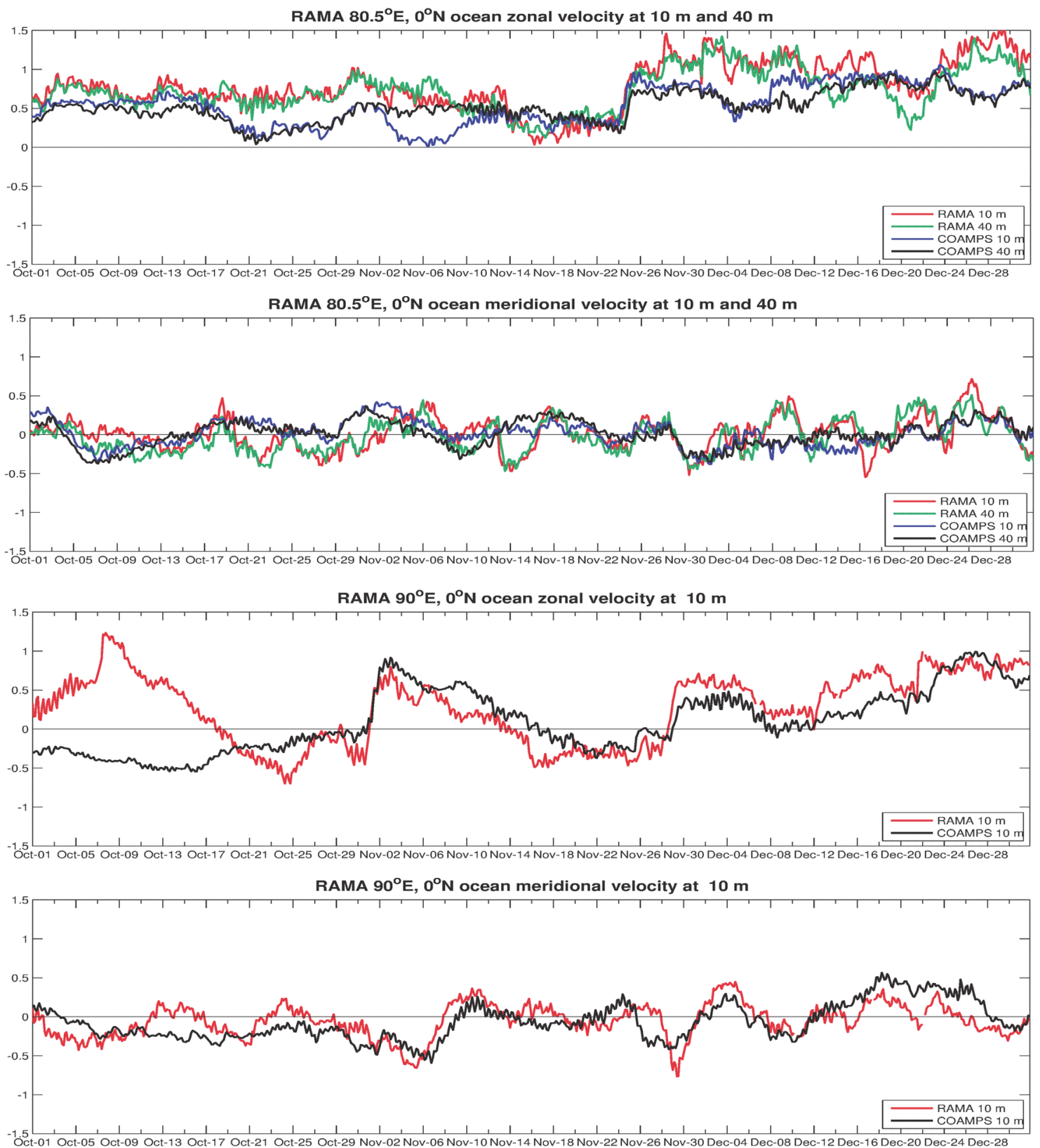

Fig. 8. Current components from the RAMA buoy and COAMPS on the equator at $80.5^{\circ} \mathrm{E}$ (two upper panels) and at $90^{\circ} \mathrm{E}$ (two lower panels).

surface jet is shifted to the north of the equator, up to about $1^{\circ}$. On the other hand, the subsurface core in the thermocline is centered very close to the equator and a zone of minimum zonal velocity is found below the base of the mixed layer, disconnecting the surface and subsurface jets. Also note that the subsurface jet looses its strength and propagates slowly downward with time. This disconnect between the directly wind driven surface jet, i.e., Yoshida jets, which changes on time scales of days, and the thermocline jet, i.e., Wyrtki jet, which changes on a longer time scale and has westward propagation, is what suggests that they 

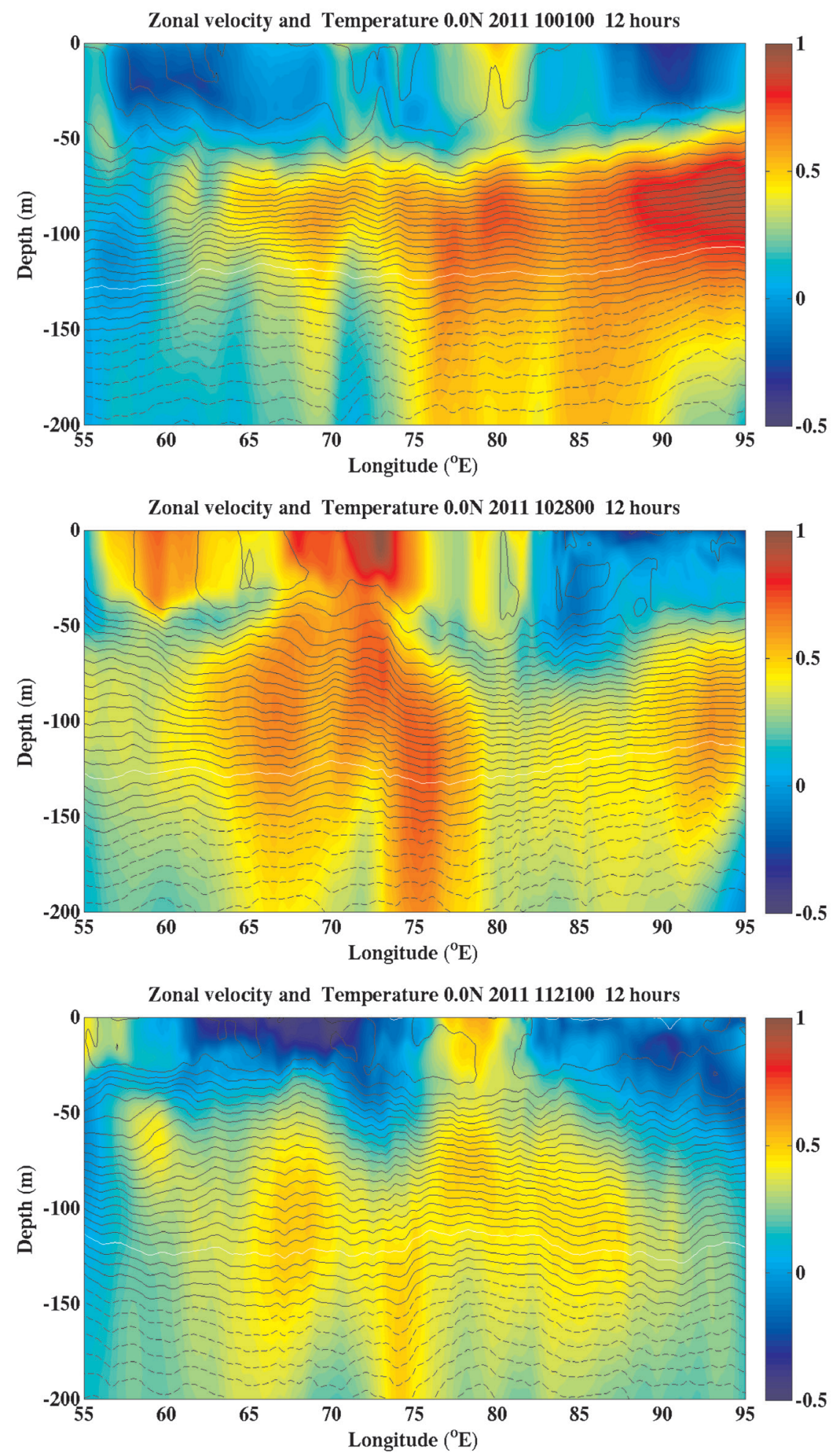

Fig. 9. Daily averaged zonal current velocity along the equator (color) and temperature (contours) on 1 Oct. (top), 28 Oct. (middle) and 21 Nov. 2011 (bottom). Contour interval is $0.5^{\circ} \mathrm{C}$. The $20^{\circ} \mathrm{C}$ contour is white, and contours for $17.5^{\circ} \mathrm{C}$ and lower are shown as dashed lines. 

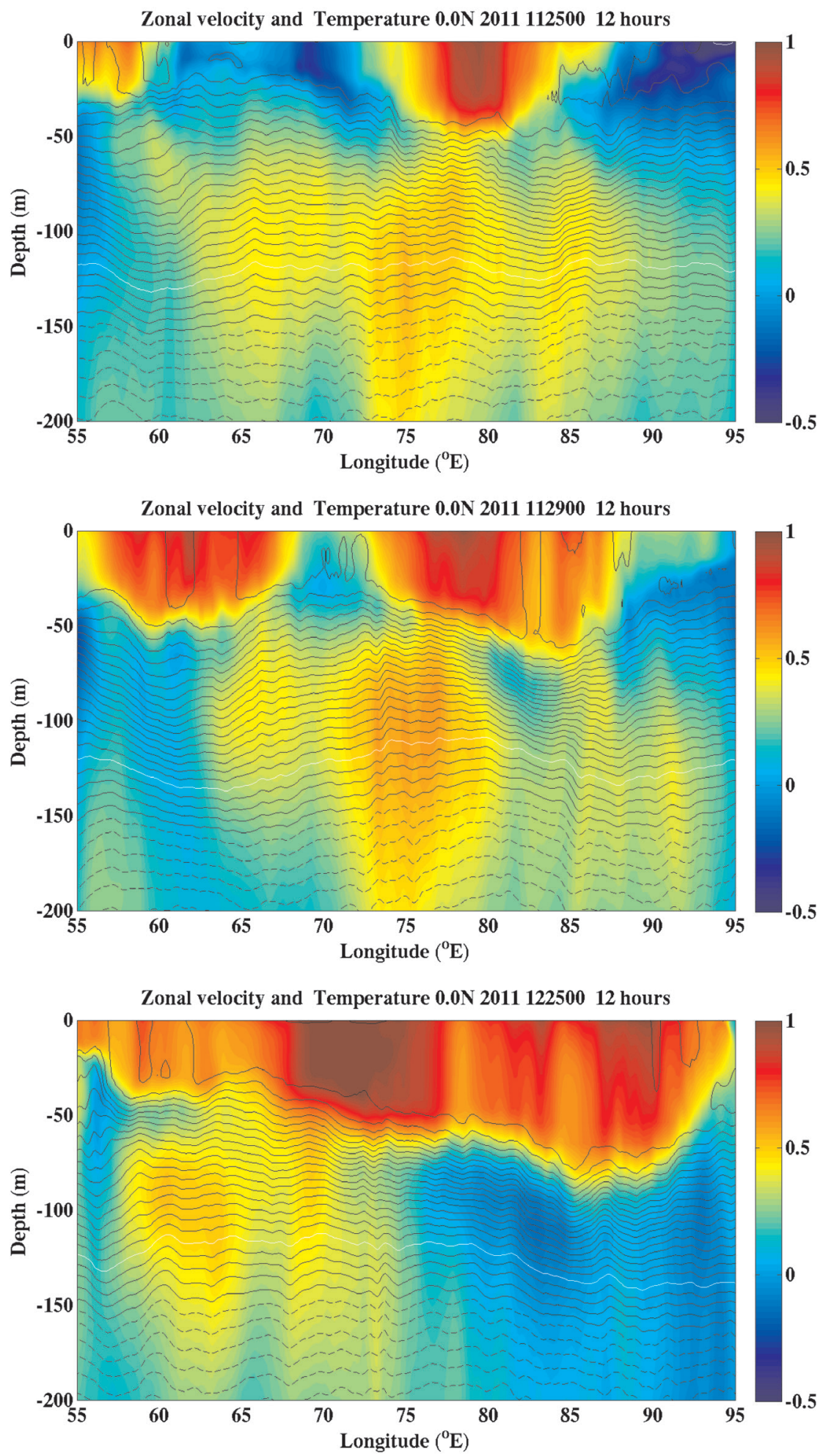

Fig. 10. Same as Fig. 9, but for 25 Nov. (top), 29 Nov. (middle), and 25 Dec. 2011 (bottom). 

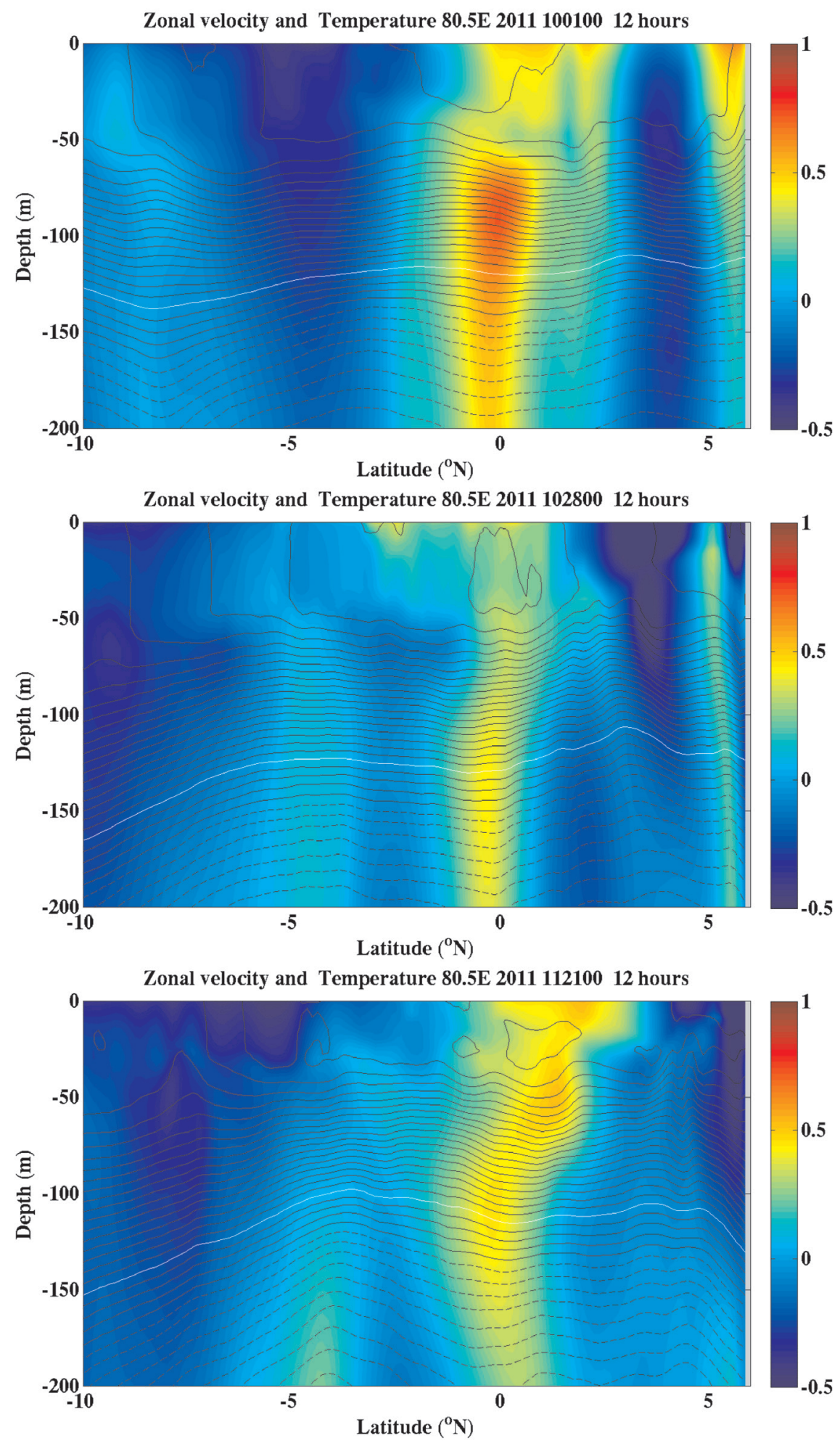

Fig. 11. Daily averaged zonal current velocity (color) and temperature (contours) along $80.5^{\circ} \mathrm{E}$ on 1 Oct. (top), 28 Oct. (middle), and 21 Nov. 2011 (bottom). Contour interval is $0.5^{\circ} \mathrm{C}$. The $20^{\circ} \mathrm{C}$ contour is white, and contours for $17.5^{\circ} \mathrm{C}$ and lower are shown as dashed lines. 

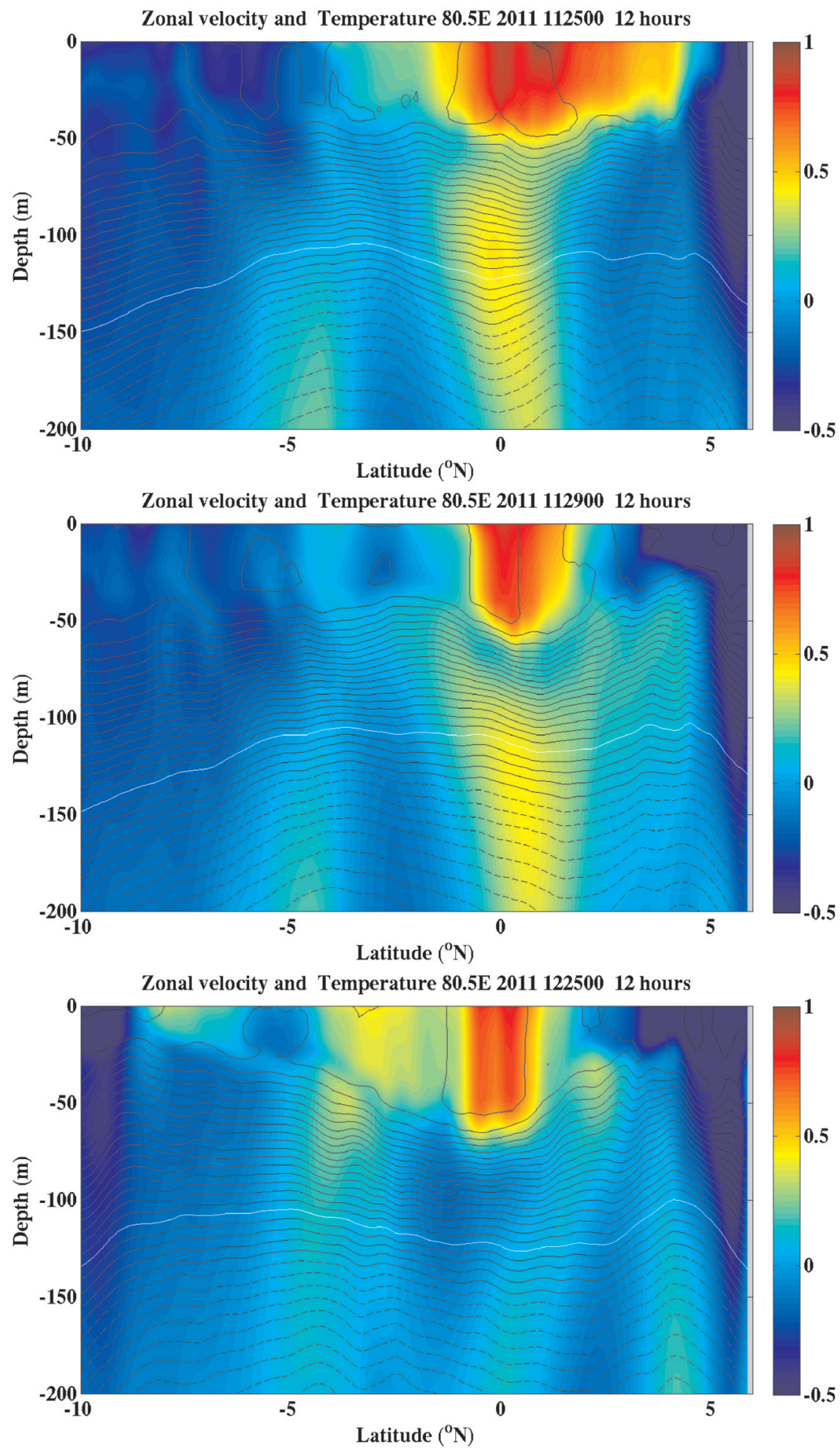

Fig. 12. Same as Fig. 11, but for 25 Nov. (top), 29 Nov. (middle), and 25 Dec. 2011 (bottom). 

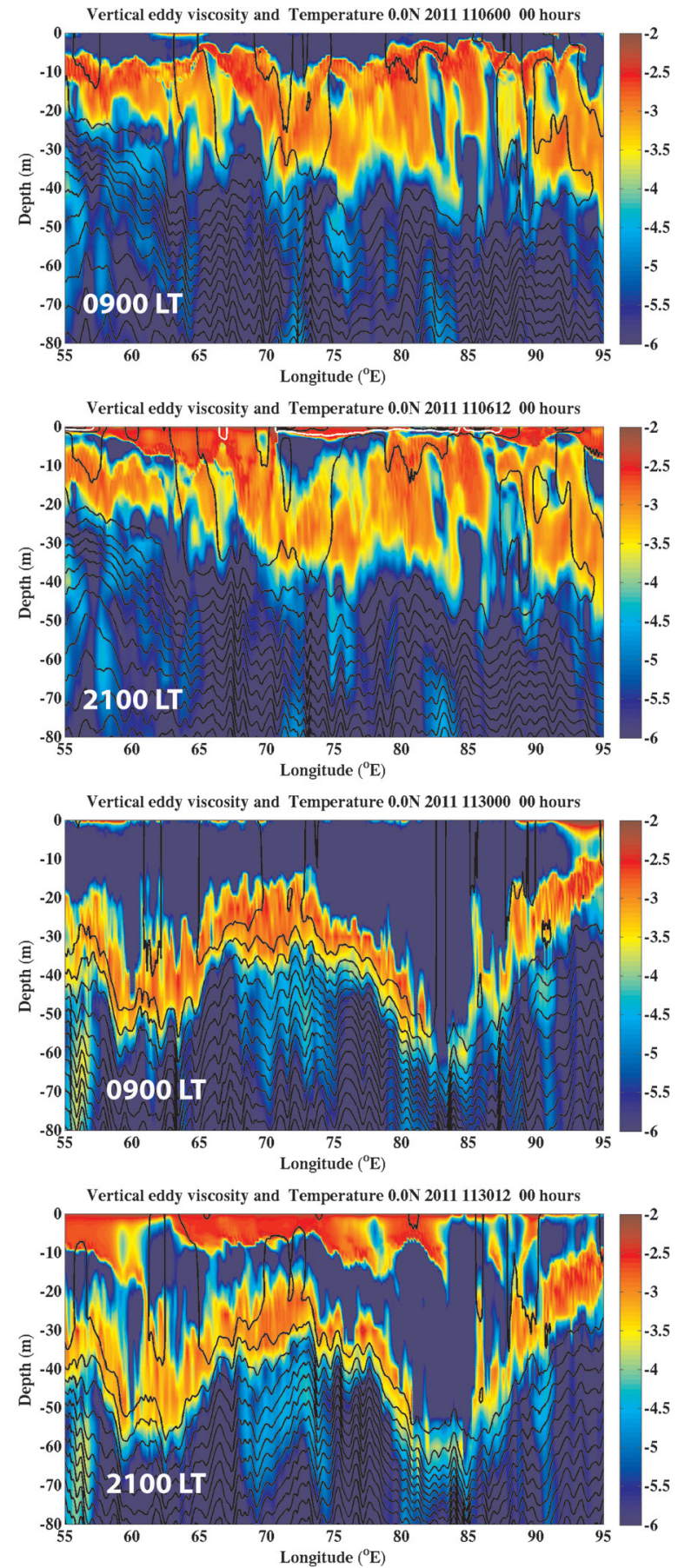

Fig. 13. Instantaneous sections of eddy viscosity on 6 Nov. in the morning at 0900 local time (a) and in the evening at 2100 local time (b) during the suppressed phase of the MJO. Below are similar plots from 30 Nov. during the active phase of the MJO. are distinct phenomena.

\section{Vertical mixing along the equator}

The mixed layer has a large depth variation during light winds and remains deep during wind events, as shown earlier. Figures 13a and 13b show the eddy viscosity along the equator during the dry or inactive MJO phases with light winds and a relatively shallow mixed layer in the morning when diurnal heating starts. During the day, the mixed layer becomes shallow and vertical shear increases. In the evening, by $9 \mathrm{pm}$ local time, eddy viscosity is further increased when convection starts. There is shear at the base of the mixed layer at all times keeping the eddy viscosity large in the upper thermocline. During the active MJO phase (Figs. 13c, d), winds deepen the mixed layer. Shear is confined to the base of the mixed layer. There is still high eddy viscosity at night from the surface to a depth of about $10 \mathrm{~m}$, but since the mixed layer already is deep, the mixing due to night time cooling does not reach the thermocline. Note that high eddy viscosity is persistent at the base of the mixed layer where high vertical shear is found (Figs. 10-12).

\section{Heat storage and equatorial wave dynamics}

It is apparent that equatorial dynamics play an important role in the direct response to the MJO. The feedback to the atmosphere is less clear, although SST anomalies play a role (e.g., Flatau et al. 1997; Wang and Xie 1998; Hendon 2005; Zhang 2005; Fu et al. 2008; Zhang 2013). The heat content of the upper ocean provides a measure of the heat available to the atmosphere and reveals the basin scale wave motions. Figures 14 and 15 show the 5-day averages of the vertically integrated temperature over the upper $200 \mathrm{~m}$ of the ocean. This quantity is proportional to the upper ocean heat content. Persistent features such as the Seychelles-Chagos thermocline ridge (SCTR) between the African coast and eastward past the Seychelles to Chagos is clearly seen between $5^{\circ} \mathrm{S}$ and $10^{\circ} \mathrm{S}$ on 3 Oct. Further east, between $5^{\circ} \mathrm{S}$ and $15^{\circ} \mathrm{S}$, a westward propagating deep thermocline is seen. During the next three months, the area of the SCTR is reduced by the westward propagating deep thermocline anomaly. By 3 Nov. a warm anomaly is seen on the equator between $70^{\circ} \mathrm{E}$ and $80^{\circ} \mathrm{E}$. It has the appearance of a Kelvin wave signal, but no eastward propagation. Figure 15 (top panel) shows the heat content after MJO2 on 28 Nov. A symmetric Rossby wave centered at $78^{\circ} \mathrm{E}$ is clearly seen, and an equatorial Kelvin wave is developing east of the RAMA buoy at $80.5^{\circ} \mathrm{E}$. It should also be noted that high heat content 


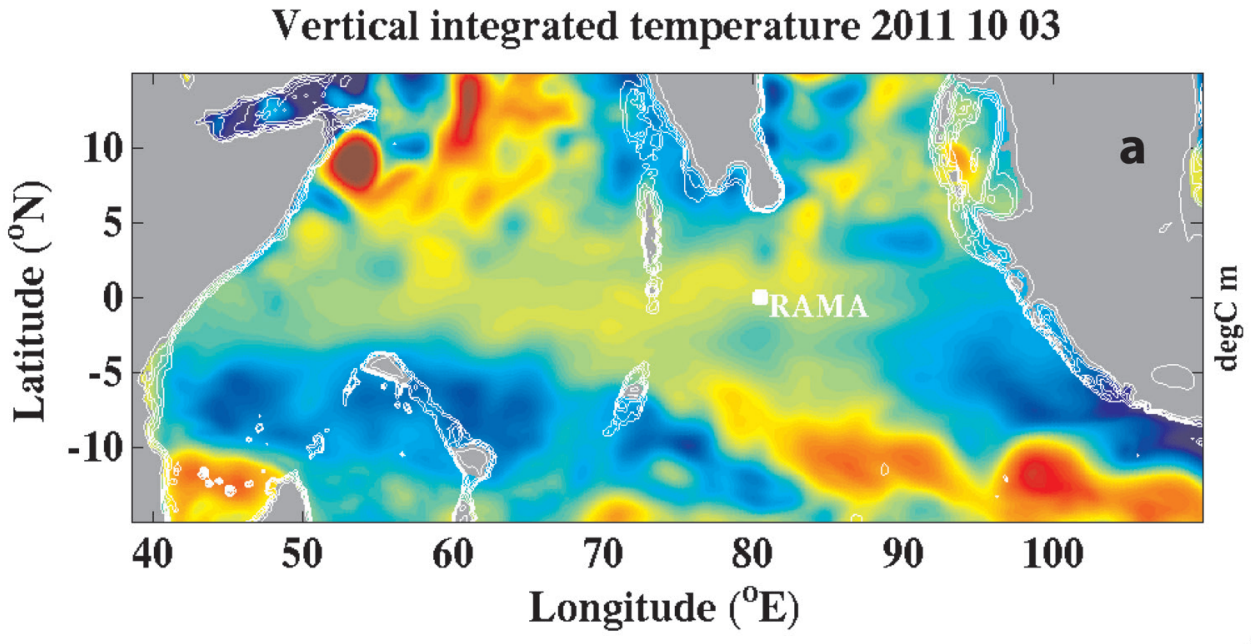

Vertical integrated temperature 20111018
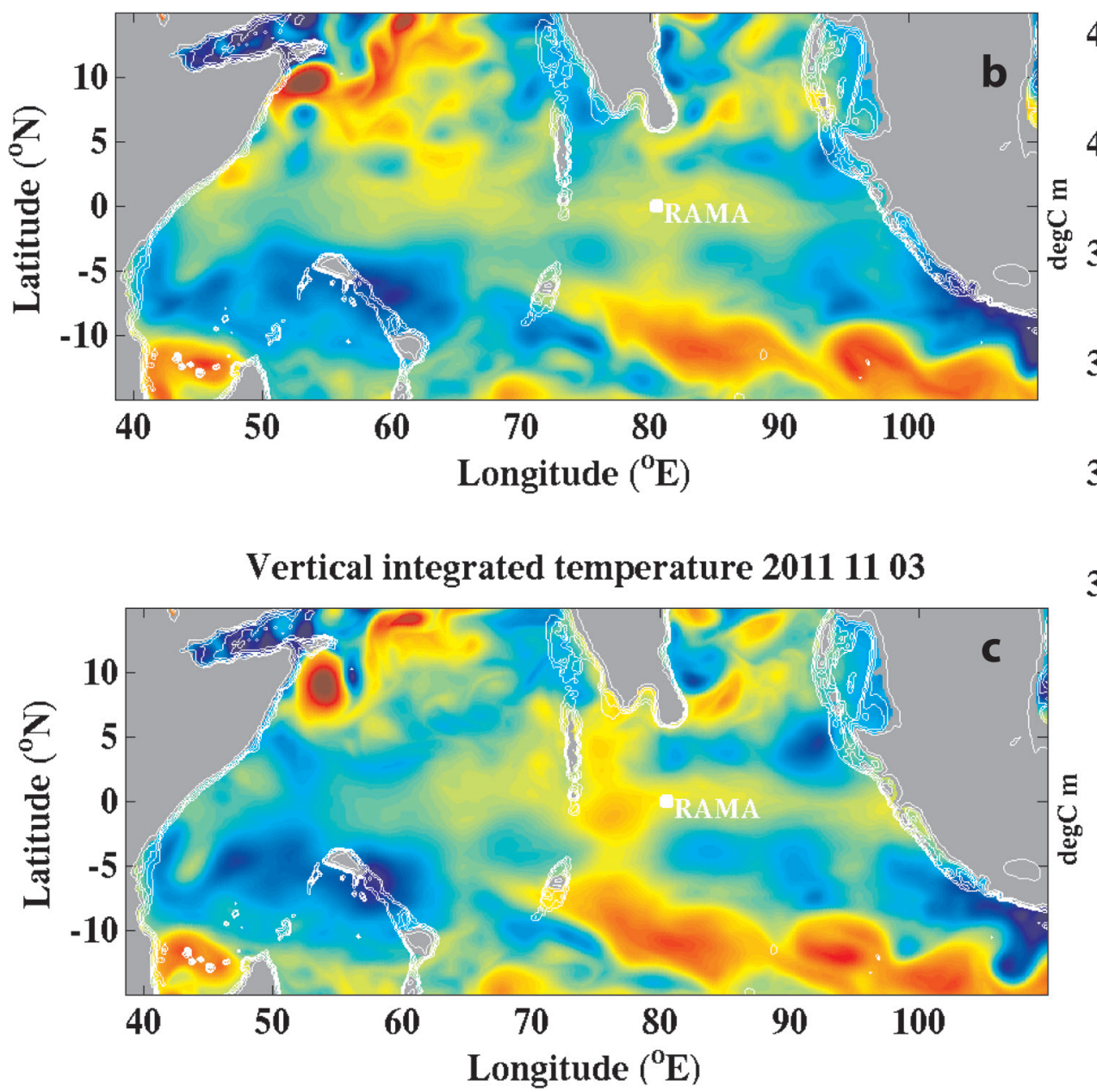


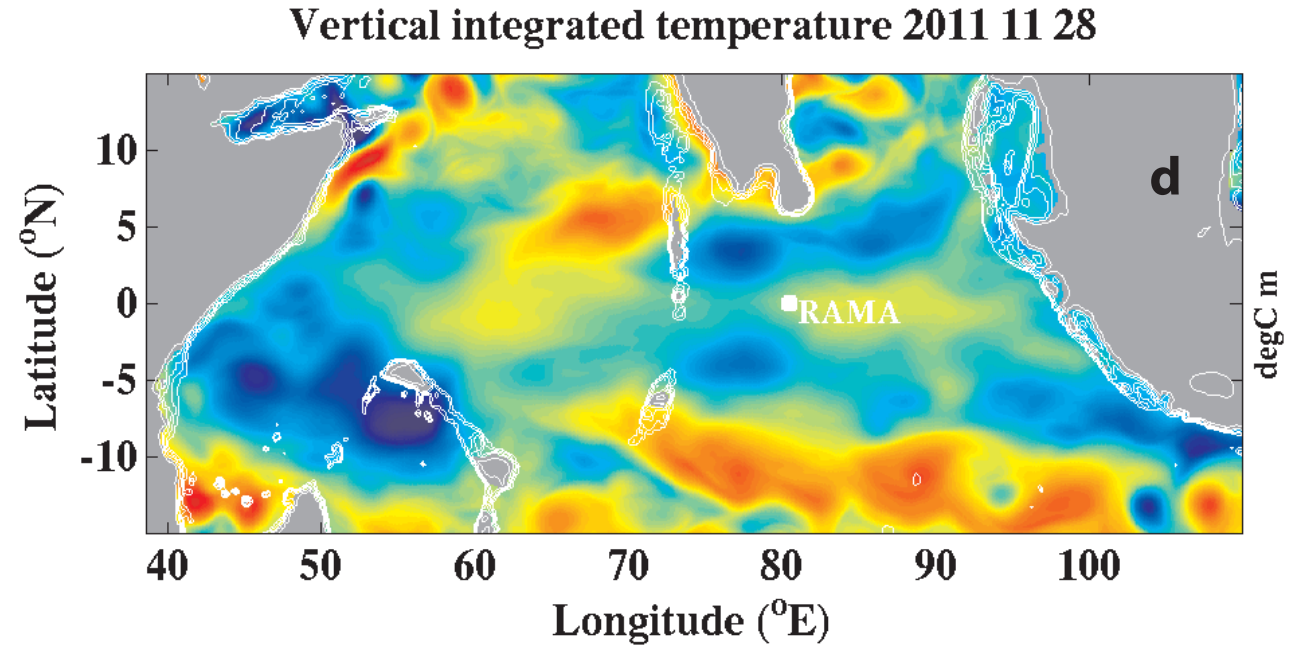

Vertical integrated temperature 20111218
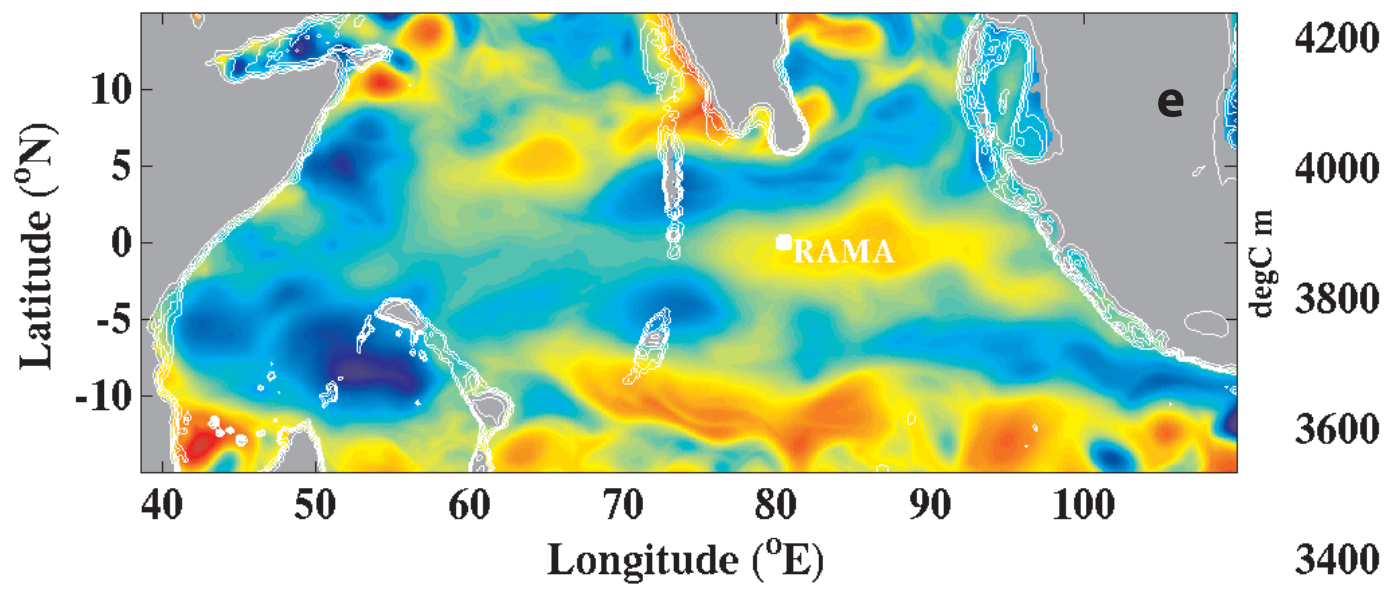

Vertical integrated temperature 20111228

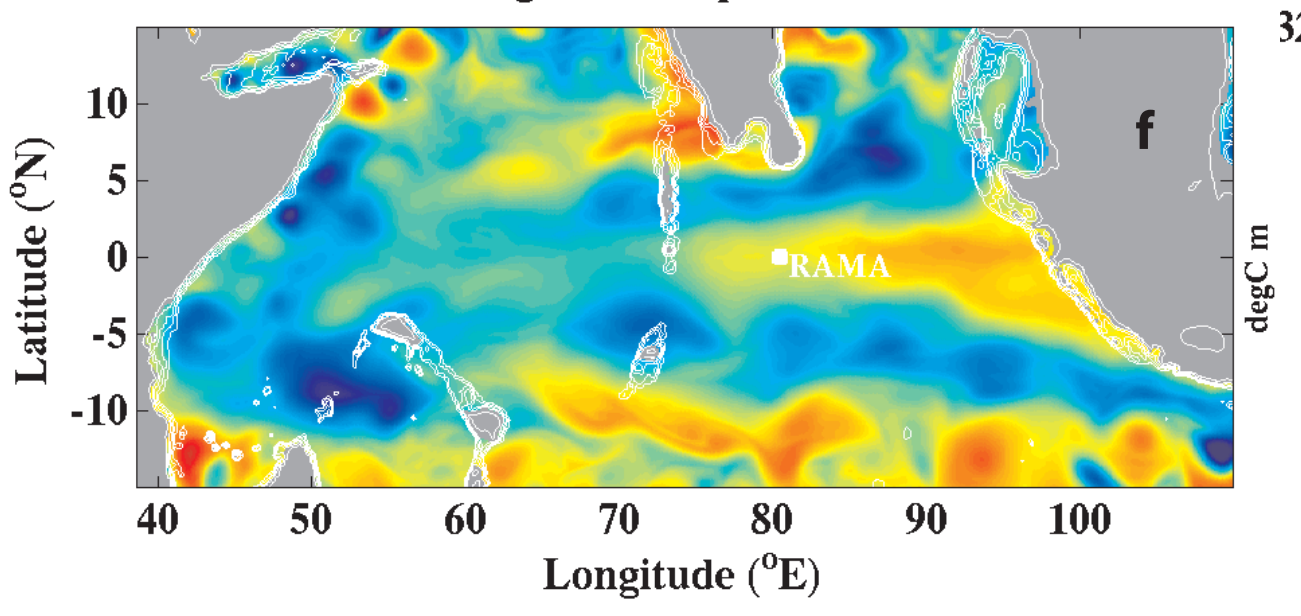

Fig. 15. Same as Fig. 14, but for 28 Nov. (d), 18 Dec. (e), and 28 Dec. 2011 (f). 

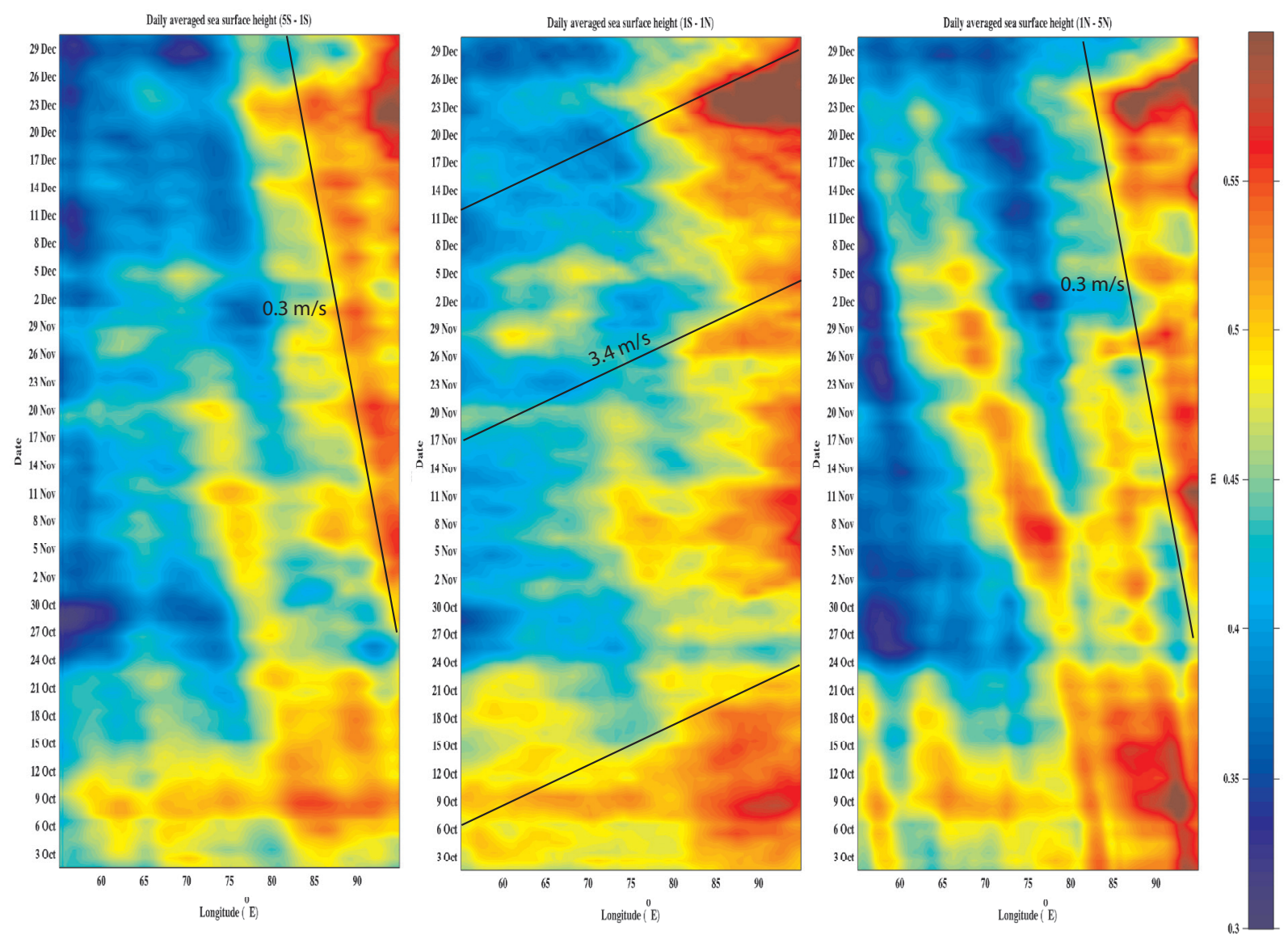

Fig. 16. Daily averaged sea surface height from 1 Oct. to 31 Dec. across the Indian ocean in three latitude bands: south of the equator from $5^{\circ} \mathrm{S}-1^{\circ} \mathrm{S}$ (left), equatorial band from $1^{\circ} \mathrm{S}-1^{\circ} \mathrm{N}$ (center), and north of the equator from $1^{\circ} \mathrm{N}-5^{\circ} \mathrm{N}$ (right). Units are meters. The black lines in the left and right panels indicate a westward propagation speed of $0.3 \mathrm{~m} \mathrm{~s}^{-1}$. The black lines in the center panel indicate eastward propagation speed of $3.4 \mathrm{~m} \mathrm{~s}^{-1}$.

anomalies are found in the central equatorial Indian Ocean between $60^{\circ} \mathrm{E}$ and $70^{\circ} \mathrm{E}$. By $18 \mathrm{Dec}$. the downwelling equatorial Kelvin is propagating eastward, has intensified, and is now extending from $80^{\circ} \mathrm{E}$ to $95^{\circ} \mathrm{E}$. On 28 Dec. the equatorial Kelvin wave reflects at the eastern boundary. The wave reflection has been observed in altimeter data (Shinoda et al. 2013b).

The eastward propagation of equatorial Kelvin waves and westward propagation of equatorial Rossby play a significant role of the oceanic response to MJO event and intra-seasonal oscillations (e.g., Han 2005). Figure 16 shows the sea surface height response in COAMPS during the 3-month model integration. In the center panel, which shows sea level on the equator, fast eastward downwelling equatorial Kelvin waves are found. The phase speed of the waves is close to $3.4 \mathrm{~m} \mathrm{~s}^{-1}$, as indicated by black lines in the center panel. As expected from equatorial wave theory (e.g., Matsuno 1966), the off-equatorial response is an upwelling symmetric equatorial Rossby wave in the open ocean. Left and right panels in Fig. 16 show a westward propagation with a phase speed close to 0.3 $\mathrm{m} \mathrm{s}^{-1}$, as shown by the black lines in the two panels. The spatial signatures of those waves are clearly seen in Fig. 15. As the Kelvin wave reflects at the eastern boundary of the Indian Ocean, a westward downwelling equatorial Rossby wave is generated (Fig. 16).

The Yoshida jets have a large impact on the advection of low-salinity water in the eastern Indian Ocean in November and December 2011. Figure 17 shows the eastward progression of the Yoshida jets during this time. The advection of high-salinity water with origin in the Arabian Sea is advected to the east and displaces low-salinity water both north and south 

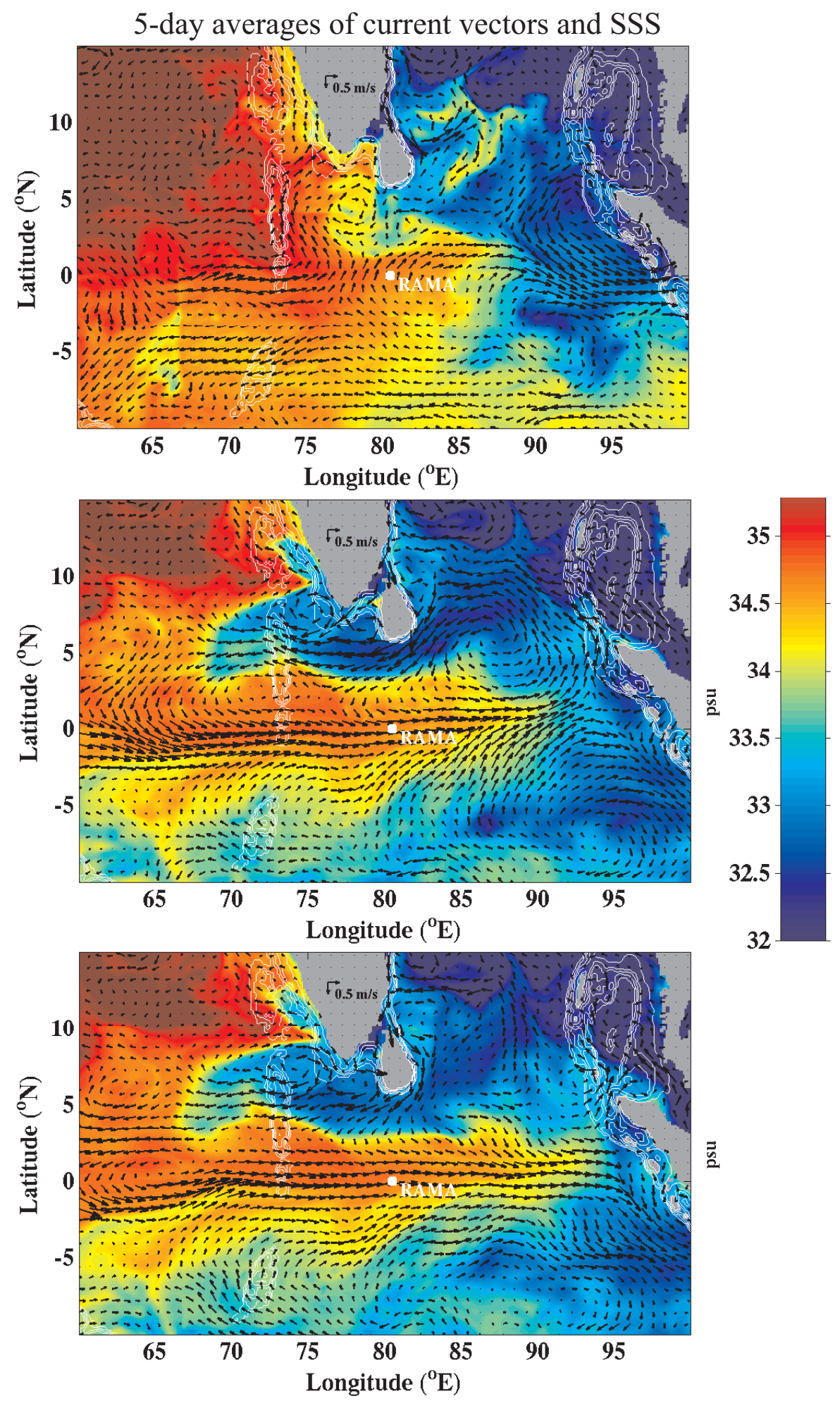

Fig. 17. Surface currents and sea surface salinity averaged over five days: 1-5 Nov. 2011 (top) after MJO1, 21-25 Dec. 2011 (center) after MJO3, and 26-31 Dec. 2011 when reflection of the equatorial Kelvin wave is under way (bottom). 
of the equator. This displacement of low-salinity water was also observed by Aquarius measurements (Shinoda 2013b).

\section{Summary and discussion}

The COAMPS was configured for the Indian Ocean using two 2-way nested high-resolution grids for the atmosphere fully coupled with a 6 min coupling interval to an ocean circulation model. A unique feature about the coupled model is the high vertical resolution of $0.5 \mathrm{~m}$ in the upper $10 \mathrm{~m}$ of the ocean, which enables the model to resolve the diurnal cycle.

The MJO affects sea surface temperature and current in the equatorial region of the Indian Ocean. During the suppressed or inactive phase of the MJO, SST is high and increasing. With the onset of the active phase, increased wind and consequently latent heat flux increases from the ocean to the atmosphere quickly lowers the SST. However, the most important cause for the cooling of the upper ocean in the COAMPS simulation was a decrease in solar radiation (not shown).

The evolution of the heat content is highly impacted by the seasonal cycle of westward propagating Rossby waves in the southern Indian Ocean as well as equatorial dynamics forced by MJO events. The westward propagation of Rossby waves will eventually impact the western Indian Ocean, and it has been shown that downwelling equatorial Rossby waves are causing temperature increases of up to $1^{\circ} \mathrm{C}$ in the area of MJO initialization (Webber et al. 2012; Shinoda et al. 2013b). The results of analyses of MJO events by Webber et al. (2013) show that triggering of primary MJO events are consistent with the arrival of downwelling symmetric mode 1 equatorial Rossby waves.

In summary, the Yoshida jet generated near $80^{\circ} \mathrm{E}$ during $\mathrm{MJO} 2$ deepens the thermocline, thereby increasing the heat content along the equator by converging transport from regions within an equatorial deformation radius on each side of the equator. The symmetric Rossby wave response is seen clearly near $77^{\circ} \mathrm{E}$. After $\mathrm{MJO} 3$ in December, the Yoshida jet reaches the coast of Sumatra and causes downwelling, deepening of the thermocline on the equator (Fig. 10, bottom panel), and raising the thermocline off the equator, poleward of $5^{\circ}$ (Fig. 15f). It has been proposed that the westward propagating Rossby waves traveling westward and raising the thermocline may set the favorable conditions for subsequent MJOs (Webber et al. 2012). The mechanism would be that a shallower thermocline when reaching the western
Indian Ocean will result in a stronger than average air-sea interaction, allowing SST to increase rapidly. This theory has yet to be validated by observations.

\section{Acknowledgments}

We wish to thank the following colleagues at NRLSSC: Timothy Campbell and Richard Allard for assistance with COAMPS development, Paul Martin for NCOM development, Lucy Smedstad for her assistance with providing global model output for boundary and initial conditions, and Jan Dastugue for help with figures.

This work was supported by The Office of Naval Research under Program Element 601153N, and computing resources were provided by the Department of Defense High Performance Computing Modernization Program. Toshiaki Shinoda is supported by NOAA grant NA15OAR431074 and NSF grant AGS-1347132.

\section{References}

Allard, R. A., T. J. Campbell, T. A. Smith, T. G. Jensen, J. A. Cummings, S. Chen, J. Doyle, X. Hong, R. J. Small, and S. N. Carroll, 2010: Validation Test Report for the Coupled Ocean/Atmosphere Mesoscale Prediction System (COAMPS) Version 5.0. NRL/MR/7320-109283, Naval Research Laboratory, $160 \mathrm{pp}$.

Barron, C. N., A. B. Kara, P. J. Martin, R. C. Rhodes, and L. F. Smedstad, 2006: Formulation, implementation and examination of vertical coordinate choices in the Global Navy Coastal Ocean Model (NCOM). Ocean Modelling, 11, 347-375.

Blumberg, A. F., and G. L. Mellor, 1987: A description of a three-dimensional coastal ocean circulation model. Three-Dimensional Coastal Ocean Models. Heaps, N. S. (ed.), American Geophysical Union, Washington D.C., $1-16$.

Cane, M., and D. W. Moore, 1981: A note on low-frequency equatorial basin modes. J. Phys. Oceanogr., 11, $1578-1584$.

Chen, S, J. Cummings, J. Doyle, R. Hodur, T. Holt, C.-S. Liou, M. Liu, A. Mirin, J. Ridout, J. Schmidt, G. Sugiyama, and W. T. Thompson, 2003: COAMPS version 3 model description: General theory and equations. NRL/PU/7500-03-448, Naval Reseach Laboratory, $145 \mathrm{pp}$.

Chen, S., T. J. Campbell, H. Jin, S. Gabersek, R. M. Hodur, and P. Martin, 2010: Effect of two-way air-sea coupling in high and low wind speed regimes. Mon. Wea. Rev., 138, 3579-3602.

Chen, S., M. Flatau, T. G. Jensen, T. Shinoda, J. Schmidt, P. May, J. Cummings, M. Liu, P. E. Ciesielski, C. W. Fairall, R.-C. Lien, D. B. Baranowski, N.-H. Chi, S. de Szoeke, and J. Edson, 2015: A study of CINDY/ 
DYNAMO MJO suppressed phase. J. Atmos. Sci., 72, 3755-3779.

Cummings, J. A., 2005: Operational multivariate ocean data assimilation. Quart. J. Roy. Meteor. Soc., 131, 35833604.

Egbert, G. D., and S. Y. Erofeeva, 2002: Efficient inverse modeling of barotropic ocean tides. J. Atmos. Oceanic Technol., 19, 183-204.

Egbert, G. D., A. F. Bennett, and M. G. G. Foreman, 1994: TOPEX/Poseidon tides estimated using a global inverse model. J. Geophys. Res., 99, 24821-24852.

Fedorov, A. V., and W. K. Melville, 2000: Kelvin fronts on the equatorial thermocline. J. Phys. Oceanogr., 30, 1692-1705.

Flatau, M., P. J. Flatau, P. Phoebus, and P. P. Niiler, 1997: The feedback between equatorial convection and local radiative and evaporative processes: The implications for intraseasonal oscillations. J. Atmos. Sci., 54, 2373-2386.

Fu, X., B. Yang, Q. Bao, and B. Wang, 2008: Sea surface temperature feedback extends the predictability of tropical intraseasonal ocillation. Mon. Wea. Rev., 136, 577-597.

Gill, A. E., 1982: Atmosphere-Ocean Dynamics. Academic Press, International Geophysical Series, 30, 662 pp.

Han, W., 2005: Origins and dynamics of the 90-day and 30-60-day variations in the equatorial Indian Ocean. J. Phys. Oceanogr., 35, 708-728.

Han, W., J. P. McCreary, Jr., D. L. T. Anderson, and A. J. Mariano, 1999: On the dynamics of the eastward surface jets in the equatorial Indian Ocean. J. Phys. Oceanogr., 29, 2191-2209.

Hendon, H. H., 2005: Air-sea interaction. Intraseasonal Variability in the Atmosphere-Ocean Climate System. Lau, W. K. M., and D. E. Waliser (eds.), Springer-Praxis, Chichester, UK, 223-246.

Hodur, R. M., 1997: The Naval Research Laboratory's Coupled Ocean/Atmosphere Mesoscale Prediction System (COAMPS). Mon. Wea. Rev., 125, 14141430.

Holland, W. R., J. C. Chow, and F. Bryan, 1998: Application of a third-order upwind scheme in the NCAR ocean model. J. Climate, 11, 1487-1493.

Jensen, T. G., 1993: Equatorial variability and resonance in a wind-driven Indian Ocean model. J. Geophys. Res., 98, 22533-22552.

Jensen, T. G., T. J. Campbell, R. A. Allard, R. J. Small, and T. A. Smith, 2011: Turbulent heat fluxes during an intense cold-air outbreak over the Kuroshio Extension Region: Results from a high-resolution coupled atmosphere-ocean model. Ocean Dyn., 61, 657-674.

Joseph, S., A. J. Wallcraft, T. G. Jensen, M. Ravichandran, S. S. C. Shenoi, and S. Nayak, 2012: Weakening of spring Wyrtki jets in the Indian Ocean during 2006-2011. J. Geophys. Res., 117, C04012, doi:10.1029/2011JC007581.
Kessler, W. S., M. J. McPhaden, and K. M. Weickmann, 1995: Forcing of intraseasonal Kelvin waves in the equatorial Pacific. J. Geophys. Res., 100, 1061310631.

Langland, R. H., and N. L. Baker, 2004: A technical description of the NAVDAS adjoint system. NRL/ MR/7530-04-8746, Naval Research Laboratory, 66 pp.

Madden, R. A., and P. R. Julian, 1972: Description of global-scale circulation cells in the tropics with a 40-50 day period. J. Atmos. Sci., 29, 1109-1123.

Maloney, E. D., and J. T. Kiehl, 2002: MJO-related SST variations over the tropical eastern Pacific during Northern Hemisphere summer. J. Climate, 15, 675-689.

Martin, P. J., 2000: Description of the navy coastal ocean model version 1.0. NRL/FR/7322/00/9962, Naval Research Laboratory, $45 \mathrm{pp}$.

Matsuno, T., 1966: Quasi-geostrophic motions in the equatorial area. J. Meteor. Soc. Japan., 44, 25-43.

Matthews, A. J., P. Singhruck, and K. J. Heywood, 2007: Deep ocean impact of a Madden-Julian Oscillation observed by Argo floats. Science, 318, 1765-1769.

Matthews, A. P., D. B. Baranowski, K. J. Heywood, P. J. Flatau, and S. Schmidtko, 2014: The surface diurnal warm layer in the Indian Ocean during CINDY/ DYNAMO. J. Climate, 27, 9101-9122.

McPhaden, M. J., G. Meyers, K. Ando, Y. Masumoto, V. S. N. Murty, M. Ravichandran, F. Syamsudin, J. Vialard, L. Yu, and W. Yu, 2009: RAMA: The research moored array for African-Asian-Australian monsoon analysis and prediction. Bull. Amer. Meteor. Soc., 90, 459-480.

Mellor, G. L., 1991: An equation of state for numerical models of oceans and estuaries. J. Atmos. Oceanic Technol., 8, 609-611.

Mellor, G. L., and T. Yamada, 1982: Development of a turbulence closure model for geophysical fluid problems. Rev. Geophys. Space Phys., 20, 851-875.

Moum, J. N., S. P. de Szoeke, W. D. Smyth, J. B. Edson, H. L. DeWitt, A. J. Moulin, E. J. Thompson, C. J. Zappa, S. A. Rutledge, R. H. Johnson, and C. W. Fairall, 2014: Air-sea interactions from westerly wind bursts during the November 2011 MJO in the Indian Ocean. Bull. Amer. Meteor. Soc., 95, 1185-1199.

Nagura, M., and M. J. McPhaden, 2010: Wyrtki jet dynamics: Seasonal variability. J. Geophys. Res., 115, C07009, doi:10.1029/2009JC005922.

Nyadjro, E. S., and M. J. McPhaden, 2014: Variability of zonal currents in the eastern equatorial Indian Ocean on seasonal to interannual time scales. J. Geophys. Res., 119, 7969-7986.

O'Brien, J. J., and H. E. Hurlburt, 1974: An equatorial jet in the Indian Ocean: Theory. Science, 184, 1075-1077.

Pedlosky, J., 1979: Geophysical Fluid Dynamics. Springer-Verlag, New York, 624 pp. 
Schott, F. A., and J. P. McCreary, Jr., 2001: The monsoon circulation of the Indian Ocean. Prog. Oceanogr., 51, 1-123.

Schott, F. A., S.-P. Xie, and J. P. McCreary, Jr., 2009: Indian Ocean circulation and climate variability. Rev. Geophys., 47, RG1002, doi:10.1029/2007RG000245.

Shinoda, T., 2005: Impact of the diurnal cycle of solar radiation on intraseasonal SST variability in the western equatorial Pacific. J. Climate, 18, 2628-2636.

Shinoda, T., and H. H. Hendon, 1998: Mixed layer modeling of intraseasonal variability in the tropical western Pacific and Indian Oceans. J. Climate, 11, 2668-2685.

Shinoda, T., P. E. Roundy, and G. N. Kiladis, 2008: Variability of intraseasonal Kelvin waves in the equatorial Pacific Ocean. J. Phys. Oceanogr., 38, 921-944.

Shinoda, T., T. G. Jensen, M. Flatau, and S. Chen, 2013a: Surface wind and upper-ocean variability associated with the Madden-Julian oscillation simulated by the Coupled Ocean-Atmosphere Mesoscale Prediction System (COAMPS). Mon. Wea. Rev., 141, 22902307.

Shinoda, T., T. G. Jensen, M. Flatau, S. Chen, W. Han, and C. Wang, 2013b: Large-scale oceanic variability associated with the Madden-Julian Oscillation during the CINDY/DYNAMO field campaign from satellite observations. Remote Sens., 5, 2072-2092.

Smagorinsky, J., 1963: General circulation experiments with primitive equations: I. The basic experiment. Mon. Wea. Rev. 91, 99-164.

Waliser, D. E., K. M. Lau, and J. H. Kim, 1999: The influ- ence of coupled sea surface temperature on the Madden-Julian Oscillation: A model perturbation experiment. J. Atmos. Sci., 56, 333-358.

Wang, B., and X. Xie, 1998: Coupled modes of the warm pool climate system. Part I: The role of the air-sea interaction in maintaining the Madden-Julian Oscillation. J. Climate, 11, 2116-2135.

Webber, B. G. M., A. J. Matthews, K. J. Heywood, and D. P. Stevens, 2012: Ocean Rossby waves as a triggering mechanism for primary Madden-Julian events. Quart. J. Roy. Meteor. Soc., 138, 514-527.

Wyrtki, K., 1973: An equatorial jet in the Indian Ocean. Science, 181, 262-264.

Yanai, M., B. Chen, and W. W. Tung, 2000: The Madden-Julian oscillation observed during TOGACOARE IOP: Global view. J. Atmos. Sci., 57, 23742396.

Yoneyama, K., C. Zhang, and C. Long, 2013: Tracing pulses of the Madden-Julian oscillation. Bull. Amer. Meteor. Soc., 94, 1871-1891.

Yoshida, K., 1959: A theory of the Cromwell current (the equatorial undercurrent) and of the equatorial upwelling - an interpretation in a similarity to a coastal circulation. J. Oceanogr. Soc. Japan, 15, 159-170.

Zhang, C., 2005: Madden-Julian Oscillation. Rev. Geophys., 43, RG 2003, doi:10.1029/2004RG000158.

Zhang, C., 2013: Madden-Julian oscillation: Bridging weather an climate. Bull. Amer. Meteor. Soc., 94, 1849-1870. 